\title{
Sex-Determining Mechanisms in Insects Based on Imprinting and Elimination of Chromosomes
}

\author{
L. Sánchez \\ Centro de Investigaciones Biológicas, Consejo Superior de Investigaciones Científicas, Madrid, Spain
}

\author{
Key Words \\ Cecydomyiidae - Chromosome elimination - Chromosome \\ imprinting $\cdot$ Coccids $\cdot$ Collembola $\cdot$ Sciara $\cdot$ Sex-determining \\ mechanisms
}

\begin{abstract}
As a rule, the sex of an individual is fixed at fertilization, and the chromosomal constitution of the zygote is a direct consequence of the chromosomal constitution of the gametes. However, there are cases in which the chromosomal differences determining sex are brought about by elimination or inactivation of chromosomes in the embryo. In Sciaridae insects, all zygotes start with the XXX constitution; the loss of either 1 or $2 X$ chromosomes determines whether the zygote becomes XX (female) or X0 (male). In Cecydomyiidae and Collembola insects, all zygotes start with the XXXX constitution. If the embryo does not eliminate any $X$ chromosome, this remains $X X X X$ and develops as female, whereas if $2 X$ chromosomes are eliminated, the embryo becomes XX0 and develops as a male. In the coccids (scale insects), the chromosomal differences between the sexes result from either the elimination or the heterochromatinization (inactivation) of half of the chromosomes giving rise to haploid males and diploid females. The chromosomes that are eliminated or inactivated are those inherited from the father. Therefore, in the formation of the sex-determining chromosomal signal in
\end{abstract}

those insects, a marking ('imprinting') process must occur in one of the parents, which determines that the chromosomes to be eliminated or inactivated are of paternal origin. In this article, the sex determination mechanism of these insects and the associated imprinting process are reviewed.

(c) 2013 S. Karger AG, Basel

Males and females are different at the morphological, physiological and behavioral levels. This sexual dimorphism results from the integration of 2 processes: sex determination and sexual differentiation. Sex determination refers to the developmental program that commits the embryo to either the male or the female pathway. The genes underlying this program are the sex determination genes. Sexual differentiation refers to the expression of the sex cytodifferentiation genes (which are controlled by the sex determination genes), the expression of which give rise to the formation of the sexually dimorphic structures that characterize the male and female adults.

The animal kingdom possesses a wealth of mechanisms via which gender is decided [Bull, 1983]. This is nowhere more evident than among insects, among which all known types of sex determination mechanisms are represented [reviewed in Sánchez, 2008; Verhulst et al., 2010; Gempe and Beye, 2011]. These mechanisms can be classified into 3 main categories depending on the origin

\section{KARGER}

E-Mail karger@karger.com

www.karger.com/sxd
(C) 2013 S. Karger AG, Basel

$1661-5425 / 13 / 0083-0083 \$ 38.00 / 0$
Lucas Sánchez

Centro de Investigaciones Biológicas, Consejo Superior de Investigaciones Científicas Ramiro de Maeztu 9

ES-28040 Madrid (Spain)

E-Mail lsanchez@cib.csic.es 
of the primary sex determination signal, which can be zygotic, maternal or environmental.

As a rule, the sex of an individual is fixed at fertilization, and therefore, the chromosomal constitution of the zygote is a direct consequence of the chromosomal constitution of the gametes [Bull, 1983]. However, in other insects, such as the dipteran families Sciaridae (fungal gnats) [Du Bois, 1933; Metz, 1938] and Cecydomyiidae (gall midges) [White, 1973; Stuart and Hatchett, 1991], the chromosomal differences determining sex are brought about by elimination of sexual X chromosomes in the embryo. In Sciaridae species, all zygotes start with the XXX constitution; the loss of either 1 or $2 \mathrm{X}$ chromosomes determines whether the zygote becomes XX (female) or X0 (male). In Cecydomyiidae species, all zygotes start with the $\mathrm{X}_{1} \mathrm{X}_{1} \mathrm{X}_{2} \mathrm{X}_{2}$ constitution. If the embryo does not eliminate any $\mathrm{X}$ chromosome, this remains $\mathrm{X}_{1} \mathrm{X}_{1} \mathrm{X}_{2} \mathrm{X}_{2}$ and develops as a female, whereas if $2 \mathrm{X}$ chromosomes $\left(\mathrm{X}_{1} \mathrm{X}_{2}\right)$ are eliminated, the embryo becomes $\mathrm{X}_{1} \mathrm{X}_{2} 0$ and develops as a male. A similar situation is found in the insects Sminthurus viridis and Allacma fusca (Collembola), where the zygotes start with the chromosome constitution XXXX (female), whereas the loss of $2 \mathrm{X}$ chromosomes determines that the zygote becomes XX0 (males) [Dallai et al., 2000]. In other cases, such as the coccids (scale insects), which belong to the order Homoptera, the chromosomal differences between the sexes result from either the elimination or the heterochromatinization (inactivation) of half of the chromosomes giving rise to haploid males and diploid females [Brown and Nur, 1964; White, 1973; Brown and Chandra, 1977; Miller and Kosztarab, 1979; Herrick and Seger, 1999; Prantera and Bongiorni, 2012].

In the Sciaridae and Cecydomyiidae, the eliminated $\mathrm{X}$ chromosomes are those inherited from the father. In the coccids, the chromosome complement that becomes either eliminated or inactivated is also the one inherited from the father. Therefore, in the formation of the sexdetermining chromosomal signal in those insects, a marking ('imprinting') process must occur in one of the parents. Historically, the term 'imprinting' was coined to describe selective identification of paternal chromosomes during their elimination process in sciarids [Crouse, $1960 \mathrm{a}, \mathrm{b}]$. Nowadays, imprinting is understood in a more general sense as an epigenetic process that marks single genes - or sets of them - during gametogenesis, resulting in their differential expression in the zygote depending on its parental origin [reviewed in Sha, 2008; Macdonald, 2012]. Imprinting associated with sex determination, the subject of this article, refers to the epigenetic process that marks whole chromosomes determining their behav- ior - elimination or inactivation - in the zygote depending on their parental origin.

In this article, the sex determination mechanisms of these insects and the associated imprinting process - the molecular basis of the 'imprinting mark' - are reviewed.

\section{Sex Determination in Sciaridae}

Figure 1 shows the chromosomal cycle of sciarids with regards to its sex determination process [reviewed in Goday and Esteban, 2001]. All zygotes start with the XXX constitution, which is a consequence of the chromosome constitution of the gametes: oocytes provide $1 \mathrm{X}$ chromosome, and sperm supply $2 \mathrm{X}$ chromosomes. When the zygotic nuclei reach the egg cortex, 1 paternal X chromosome is eliminated in the somatic cells of embryos destined to be females (XX), and the 2 paternal X are eliminated in those destined to become males (X0) [reviewed in Gerbi, 1986].

The pole cells (precursors of the germ cells) are set apart at the posterior pole of the embryo [Du Bois, 1933; Berry, 1941; Perondini et al., 1986] and do not eliminate $\mathrm{X}$ chromosomes at the same time as the nuclei that will form somatic cells. Elimination of 1 paternally derived X chromosome occurs later, at the beginning of germ band segmentation; just 1 of the 2 paternal $\mathrm{X}$ chromosomes is eliminated in both male and female embryos [Berry, 1941; Rieffel and Crouse, 1966; Perondini and Ribeiro, 1997; Perondini, 1998]. Consequently, germ cells are XX and will produce either oocytes or sperm depending on the sex of the gonad, whether this is female (ovary) or male (testis), respectively. Meiosis in females is orthodox, whereas in males is aberrant (fig. 1) [Goday and Esteban, 2001]. During the first meiotic division, all the paternally derived chromosomes are eliminated in a cytoplasmic bud so that only the maternally derived chromosomes remain. During the second meiotic division, the 2 chromatids of each autosome segregate normally: 1 is located in the previous cytoplasmic bud, and the other chromatid will form the chromosome complement of the sperm. However, the 2 chromatids of the X chromosome do not segregate and are incorporated into the sperm so that the $2 \mathrm{X}$ chromosomes brought by the sperm are the sister chromatids of the maternally inherited X chromosome [Metz, 1938]. Hence, each event of meiosis in Sciara males yields 1 instead of 4 spermatozoids, containing a haploid set of autosomes and $2 \mathrm{X}$ chromosomes, all of maternal origin [Gerbi, 1986; Fuge, 1994; Esteban et al., 1997]. 
Fig. 1. The chromosomal cycle of Sciaridae species. X and A refer to sexual and autosomal chromosomes, respectively. L stands for germ-line-limited chromosomes. The maternal and paternal origin of the chromosomes is indicated by $m$ and $p$, respectively. Modified from Sánchez and Perondini [1999] and from Goday and Esteban [2001].

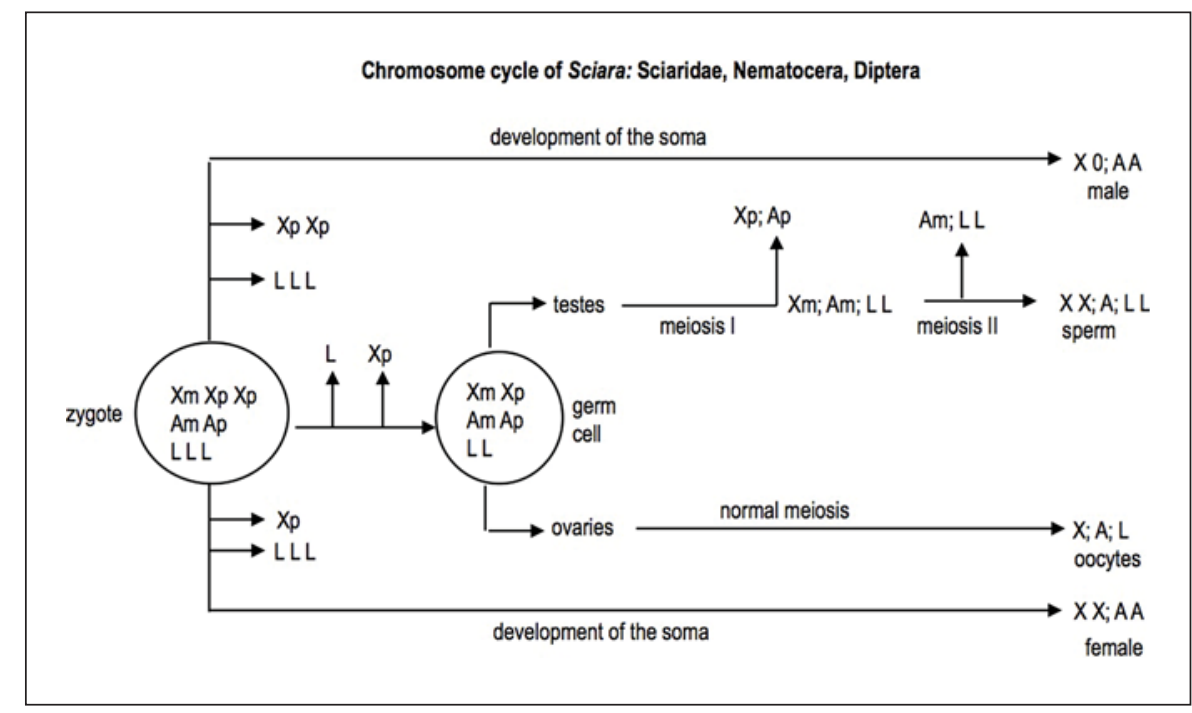

Some sciarids carry additional chromosomes, the sonamed 'L' chromosomes, which are only present in the germ cells, condense differently to the other ordinary chromosomes and replicate later in the cell cycle, as does heterochromatin [Rieffel and Crouse, 1966; Amabis et al., 1979]. S. coprophila is an example (see fig. 1). As a rule, this sciarid has generally $3 \mathrm{~L}$ chromosomes. During embryonic development, all $\mathrm{L}$ chromosomes are eliminated from the nuclei that will form the somatic cells in both sexes. Later in development, the germ cells of both sexes eliminate $1 \mathrm{~L}$ chromosome (or more but 2 if they carry more than $3 \mathrm{~L}$ chromosomes) at the same time when they eliminate 1 paternally derived X chromosome. During oogenesis, the $2 \mathrm{~L}$ chromosomes segregate normally as the sex and autosomal chromosomes so that the oocyte receives $1 \mathrm{~L}$ chromosome. During spermatogenesis, the 2 $\mathrm{L}$ chromosomes are not eliminated during the first meiotic division, and during the second meiotic division, the 2 chromatids of each $\mathrm{L}$ chromosome segregate, as do the 2 chromatids of each autosome: 1 chromatid is placed in the cytoplasmic bud, and the other 1 is incorporated in the sperm. Hence, this contributes $2 \mathrm{~L}$ chromosomes to the zygote.

\section{Monogenic and Digenic Species in Sciarids}

Some sciarids, such as $S$. coprophila, are monogenic species, which are composed of 2 types of females: gynogenic and androgenic females, which only produce females and males, respectively, in their offspring [Moses and Metz, 1928; Metz and Schmuck, 1929; Metz, 1938; Gerbi, 1986]. Gynogenic and androgenic females differ in the presence of a special X' chromosome: gynogenic females are $\mathrm{X}$ 'X, whereas androgenic females are XX. Thus, the factor for either male or female production is located on the X chromosome [Metz, 1938]. There is an inversion in the $\mathrm{X}^{\prime}$ chromosome that prevents its recombination with the homologous $\mathrm{X}$ chromosome, thus retaining the factor for female production in the X' chromosome. The gynogenic females produce 2 classes of oocytes predetermined to eliminate $1 \mathrm{X}$ chromosome of the 2 inherited from the father: the $\mathrm{X}^{\prime}$ and $\mathrm{X}$ oocytes contribute to the production of the gynogenic and androgenic females, respectively, of the following generation. The XX androgenic females produce a unique class of $\mathrm{X}$ oocytes predetermined to eliminate the $2 \mathrm{X}$ chromosomes inherited from the father. Consequently, the $\mathrm{X}$ oocytes from the androgenic females contribute to the production of X0 males of the following generation.

S. ocellaris is a digenic species, in which each female produces both males and females in the offspring. The sex ratio (number of males vs. females) of the descendants of each female, however, is highly variable, deviating from $1: 1$. Nevertheless, at the level of the whole population, the sex ratio follows a normal distribution around this value [Metz, 1938; Davidheiser, 1943; Mori et al., 1979]. In S. ocellaris, the female parent determines the sex of the offspring [Liu, 1968; reviewed in Sánchez and Perondini, 1999], as it happens in S. coprophila. The sex ratio in $S$. ocellaris depends on temperature: at $18-20^{\circ} \mathrm{C}$, the sex ratio distribution, although variable, shows a median of ap- 
proximately $50 \%$, but at $24-29^{\circ} \mathrm{C}$, the sex ratio moves significantly towards the production of more females. This change in sex ratio is not caused by a higher mortality among males, but by a transformation of males into females; this fact results in an increase in the number of embryos that eliminate 1 instead of the 2 paternally derived $\mathrm{X}$ chromosomes [Nigro et al., 2007]. Temperature-shift experiments have shown that the temperature-sensitive period for the determination of the final sex ratio is from the mid-pupa stage to the emergence of adult females [Nigro et al., 2007], the period during which oogenesis takes place [Berry, 1941]. Hence, S. ocellaris females produce at distinct temperatures different ratios of oocytes predetermined to eliminate either 1 or $2 \mathrm{X}$ chromosomes. In Sciara females, the number of oocytes is fixed during the early larval stages, and no further mitosis occurs nor are new oocytes produced in the pupal/adult stages [Berry, 1941].

A strain of $S$. ocellaris has been described that carries a sepia-X chromosome characterized by the yellow color of the adult cuticle. This chromosome causes alterations in the sex ratio towards the production of more males, without differential mortality of female embryos [Mori et al., 1979]. Moreover, the offspring of this strain contains a significant number of gynandromorphs as well - individuals with some portions of the body typically male (X0) and others typically female (XX) in which some somatic nuclei eliminate the 2 paternally derived X chromosomes whereas other nuclei eliminate only 1 [Mori et al., 1979; Mori and Perondini, 1980]. The effect of this sepia$\mathrm{X}$ chromosome occurs only when this chromosome is in the mother, supporting the contention that the number of X chromosomes eliminated in the embryo becomes determined by the mother.

S. matogrossensis shows both monogenic and digenic reproduction: some females behave as digenic, others as gynogenic, others as androgenic, and still others produce offspring with 1 predominant sex (either male or female). These offspring sex ratios are maintained in successive generations, thus suggesting that the control of the offspring ratio (either elimination of 1 or $2 \mathrm{X}$ chromosomes) may involve more than 1 locus, at least, more than 1 pair of alleles [Rocha and Perondini, 2000].

\section{A Model for the Control of Differential X Chromosome Elimination in Sciara}

Spontaneous and UV-induced deviations and mistakes in X chromosome elimination can occur in the sciarids [reviewed in Sánchez and Perondini, 1999]. Two basic types of error have been reported. The quantitative errors affect the number of paternally derived X chromosomes that are eliminated; some nuclei in the embryos derived from oocytes predetermined to eliminate $1 \mathrm{X}$ chromosome eliminate instead the $2 \mathrm{X}$ chromosomes derived from the father, thus causing the production of gynandromorphs. The qualitative errors refer to the case in which the X chromosome that becomes eliminated is not the 1 inherited from the father but the 1 inherited from the mother, resulting from an error in the imprinting process. These errors produce mosaic individuals that contain a mixture of tissues with the normal chromosome set, X0 for males and $\mathrm{XX}$ for females, but the single $\mathrm{X}$ chromosome of males and 1 of the $2 \mathrm{X}$ chromosomes of females are patroclinous.

The results obtained in the analysis of X chromosome elimination in somatic cells of Sciara species are summarized below [see Sánchez and Perondini, 1999 for details]:

(1) The mechanism of X chromosome elimination is similar in monogenic and digenic species.

(2) A maternal factor (MF) is produced during oogenesis, which accumulates in the oocyte and then governs the elimination of the $\mathrm{X}$ chromosome in the developing zygote.

(3) The embryo eliminates either 1 or $2 \mathrm{X}$ chromosomes inherited from the father independently of the number of X chromosomes initially present in the zygote.

(4) There are 2 independent mechanisms involved in the elimination of $\mathrm{X}$ chromosomes. One regulates the number of $\mathrm{X}$ to be eliminated and resides in the cytoplasm, the other identifies the $\mathrm{X}$ to be eliminated and seems to be nuclear.

(5) Among the embryos produced by gynogenic mothers, errors more frequently occur in XXX zygotes that develop into androgenic females than in X'XX zygotes that become gynogenic females.

(6) Errors are rare in XXX embryos produced by androgenic females.

Two models have been discussed for the control of differential X chromosome elimination in sciarid flies, which differ in the role played by the MF that controls the number of X chromosomes that become eliminated (the interested reader can find a more detailed discussion in Sánchez and Perondini [1999]):

(1) In the 1-factor model, it is assumed that the MF promotes the elimination of the $\mathrm{X}$ chromosome and binds to the paternally inherited $\mathrm{X}$ chromosome causing its elimination. Under this scenario, the oocytes containing a higher amount of MF would eliminate $2 \mathrm{X}$ chromosomes, and those oocytes containing less amount of MF will eliminate $1 \mathrm{X}$ chromosome.
Sánchez 
(2) In the 2-factor model, it is assumed that the MF prevents the elimination of the $\mathrm{X}$ chromosome. Under this scenario, it is assumed that a chromosomal factor CF binds to the paternal $\mathrm{X}$ chromosome causing its elimination. This factor is produced in limited amounts and at similar concentrations in both male and female embryos. The MF interacts with CF, inactivating it, so that the CFMF complex cannot interact with the paternal X chromosome. Therefore, the number of X chromosomes eliminated depends on the amount of free CF, which in turn depends on the amount of MF. Under this scenario, the oocytes containing a higher amount of MF would eliminate $1 \mathrm{X}$ chromosome, and those oocytes containing less amount of MF would eliminate $2 \mathrm{X}$ chromosomes.

In both models, it is assumed that imprinting, in relation to the identification of the X chromosome to be eliminated, occurs in the maternal chromosomes and not in the paternal counterparts. The imprinted state would be manifested by the inability of the maternal $\mathrm{X}$ chromosome to bind MF, in the 1-factor model, or CF, in the 2 -factor model, and then, the maternally inherited $\mathrm{X}$ chromosome is not eliminated.

\section{Genes Homologous to the Drosophila Sex Determination Genes in Sciara}

The search for genes homologous to the sex determination genes of Drosophila melanogaster has been undertaken [reviewed in Sánchez, 2008; Verhulst et al., 2010; Gempe and Beye, 2011]. The gene Sex lethal (Sxl) has been characterized in S. ocellaris [Ruiz et al., 2003], S. coprophila, Rynchosciara americana, and Trichosia pubescens [Serna et al., 2004]. It is not regulated in a sex-specific fashion, and therefore, the same $S x l$ transcript encoding the unique functional SXL protein is found in both males and females. Furthermore, it has been observed that the Sciara SXL protein binds to the polytene chromosome regions of all actively transcribing chromosomes, colocalizing with RNA polymerase II, as expected for a general splicing factor, but not with RNA polymerase I. This was observed in both sexes in S. ocellaris [Ruiz et al., 2003] and in S. coprophila, R. americana and T. pubescens [Serna et al., 2004]. Thus, in the sciarids, the $S x$ lgene does not appear to play the key discriminating role in sex determination that it plays in Drosophila.

The transformer2 (tra2) genes of S. ocellaris and $S$. coprophila have been also characterized [Martín et al., 2011]. The Sciara TRA2 proteins showed the features of the SR protein family, and their comparison with the

Imprinting and Sex Determination
TRA2 proteins of other insects revealed the greatest degree of conservation in the RRM domain and linker region, involved in RNA binding. In contrast, the RS1 and RS2 domains showed extensive variation with respect to their number of amino acids and their arginine-serine dipeptide content. The expression of S. ocellaris TRA2 protein in Drosophila XX pseudomales lacking the endogenous tra2 function caused their partial feminization. The Sciara TRA2 protein was able to form a complex with the endogenous Drosophila TRA protein that controls the female-specific splicing of the Drosophila doublesex ( $d s x$ ) pre-mRNA. However, it appears that the complex formed between the Drosophila TRA protein and the Sciara TRA2 protein is less effective at inducing the female-specific splicing of the endogenous Drosophila $d s x$ pre-mRNA than the own Drosophila TRA-TRA2 complex, suggesting the existence of species-specific coevolution of the TRA and TRA2 proteins.

When sex determination is based on chromosome differences, one sex being homomorphic and the other heteromorphic for the sex chromosomes, a process named dosage compensation has evolved to eliminate the differences in the 2 sexes between the products encoded by genes located on the sex chromosomes and those located on the autosomes. In D. melanogaster, dosage compensation is achieved in males by hypertranscription of the single $\mathrm{X}$ chromosome and is controlled by the male-specific lethal ( $m s l$ ) genes: the protein-coding genes maleless (mle), $m s l-1, m s l-2$, and $m s l-3$ plus RNA on the X1 and X2 (roX1 and roX2) genes that produce RNAs lacking any significant open reading frame [reviewed in Lucchesi, 2009; Conrad and Akhtar, 2012]. In Sciara, gender depends on chromosome constitution; males are $\mathrm{X} 0 ; 2 \mathrm{~A}$, and females are $2 \mathrm{X} ; 2 \mathrm{~A}$; there exists also dosage compensation, which appears to be achieved by hypertranscription of the single X chromosome in males [da Cunha et al., 1994], although different proteins seem to implement dosage compensation in Drosophila and Sciara [Ruiz et al., 2000].

\section{Sex Determination in Cecydomyiidae}

In Cecydomyiidae, monogenic and digenic species have been identified [Painter, 1930; Barnes, 1958; Gallun et al., 1961; Stuart and Hatchett ,1988b]. The genetic basis of sex determination in Cecydomyiidae is less understood than in Sciaridae species. Figure 2 shows the chromosomal cycle of the paradigmatic species Mayetiola destructor (Hessian fly) [Stuart and Hatchett, 1988a, b, 1991]. They 
Fig. 2. The chromosomal cycle of Cecydomyiidae species. $\mathrm{X}$ and $\mathrm{A}$ refer to sexual and autosomal chromosomes, respectively. E stands for germ-line-limited chromosomes. The maternal and paternal origin of the chromosomes is indicated by $\mathrm{m}$ and $\mathrm{p}$, respectively. Modified from Stuart and Hatchett [1991].

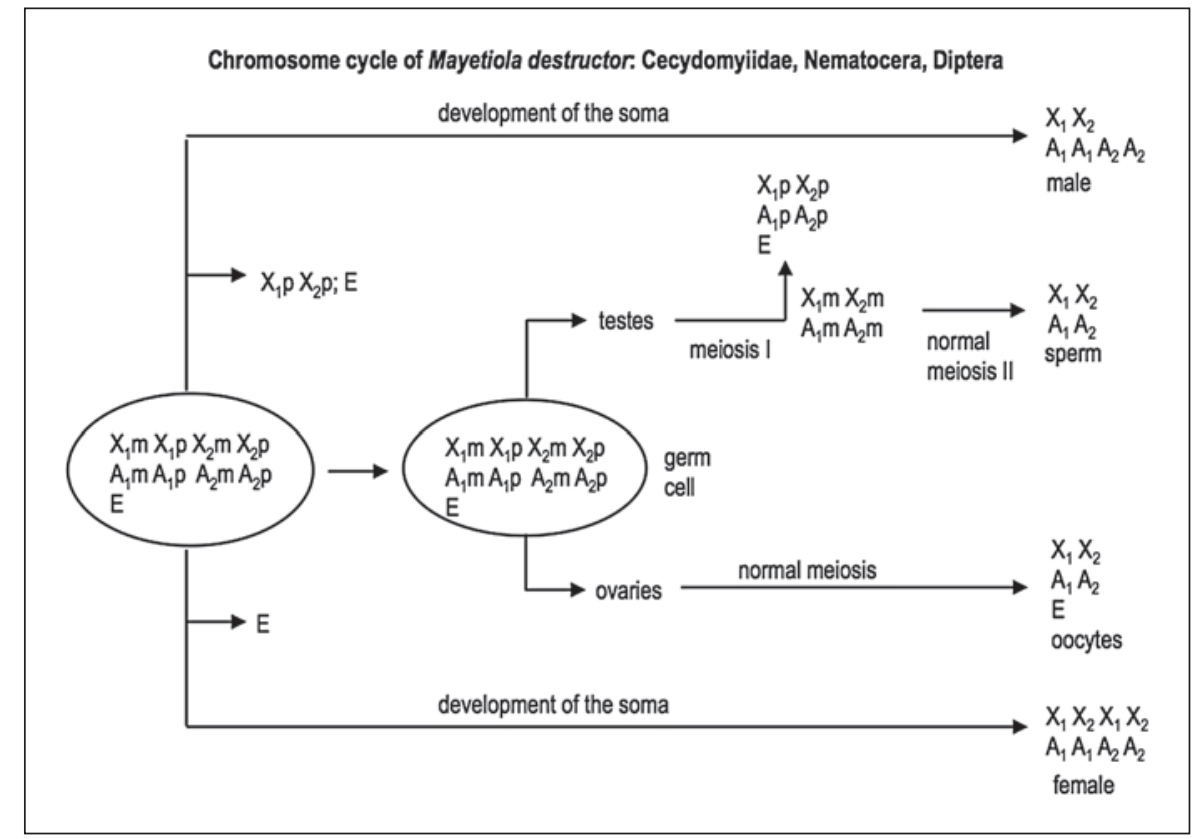

carry $2 \mathrm{X}$ chromosomes, $\mathrm{X}_{1}$ and $\mathrm{X}_{2}$, being the males $\mathrm{X}_{1} \mathrm{X}_{2} 0$ and the females $\mathrm{X}_{1} \mathrm{X}_{1} \mathrm{X}_{2} \mathrm{X}_{2}$. In addition, they also contain the so-called germ-line-limited $\mathrm{E}$ chromosomes, which are only present in the germ line of both sexes. All zygotes start with the $\mathrm{X}_{1} \mathrm{X}_{1} \mathrm{X}_{2} \mathrm{X}_{2}$ chromosome constitution plus the $\mathrm{E}$ chromosomes. These latter chromosomes are all eliminated from the nuclei that will form the somatic cells in both sexes. If a pair $\mathrm{X}_{1}$ and $\mathrm{X}_{2}$ chromosomes are also eliminated, the embryo will develop as male, whereas if no X chromosomes are eliminated, it will develop as female. The $\mathrm{X}$ chromosomes that are eliminated are those inherited from the father so that an imprinting process exists also in Mayetiola. Oogenesis is orthodox, and the oocytes carry a haploid set of all normal chromosomes plus a haploid set of E chromosomes. Spermatogenesis, however, is aberrant: during the first meiotic division, all the paternally derived normal chromosomes ( $\mathrm{X}$ and autosomes) and all the $\mathrm{E}$ chromosomes are eliminated, and the second meiotic division is orthodox with the production of 2 sperm, each 1 carrying a haploid set of normal chromosomes (X and autosomes of maternal origin). Thus, both Cecydomyiidae and Sciaridae species share some features regarding their chromosomal cycles in relation to sex determination.

The models described above for the control of X chromosome elimination in Sciaridae can apply to Cecydomyiidae species. The main difference between these species is that in Sciaridae, there is always elimination of $\mathrm{X}$ chromosomes, either 1 (male) or 2 (female), whereas in Cecydomyiidae, there is elimination of 1 set $\mathrm{X}_{1} \mathrm{X}_{2}$ of chromosomes (male) or no elimination (female). Therefore, following the models described above, in Cecydomyiidae species, some oocytes will contain a MF whereas others do not. Like in Sciaridae, imprinting would be established in the mother, and the imprinted state would mean inability of the maternally derived $\mathrm{X}_{1} \mathrm{X}_{2}$ chromosomes to bind the elimination factor.

\section{Sex Determination in Collembola}

Collembola (springtails) are one of the first insect orders that appeared on Earth [Whalley and Jarzembowski, 1981]. The genetic basis underlying sex determination of these insects is beginning to be understood. Figure 3 shows the chromosomal cycle of the paradigmatic species A. fus$c a$ and $S$. viridis in relation to sex determination [Dallai et al., 1999, 2000, 2001]. In these species, males are XX0 and females XXXX. All zygotes start with the XXXX chromosome constitution. If no $\mathrm{X}$ chromosomes are eliminated, the embryos develop as females, which have an orthodox oogenesis producing XX oocytes. If $2 \mathrm{X}$ chromosomes are eliminated from the nuclei of the future somatic cells and germ cells, the embryo will become XX0 and will develop as male. Spermatogenesis is aberrant in that the 0-bearing spermatocytes from the first meiotic division will degen- 


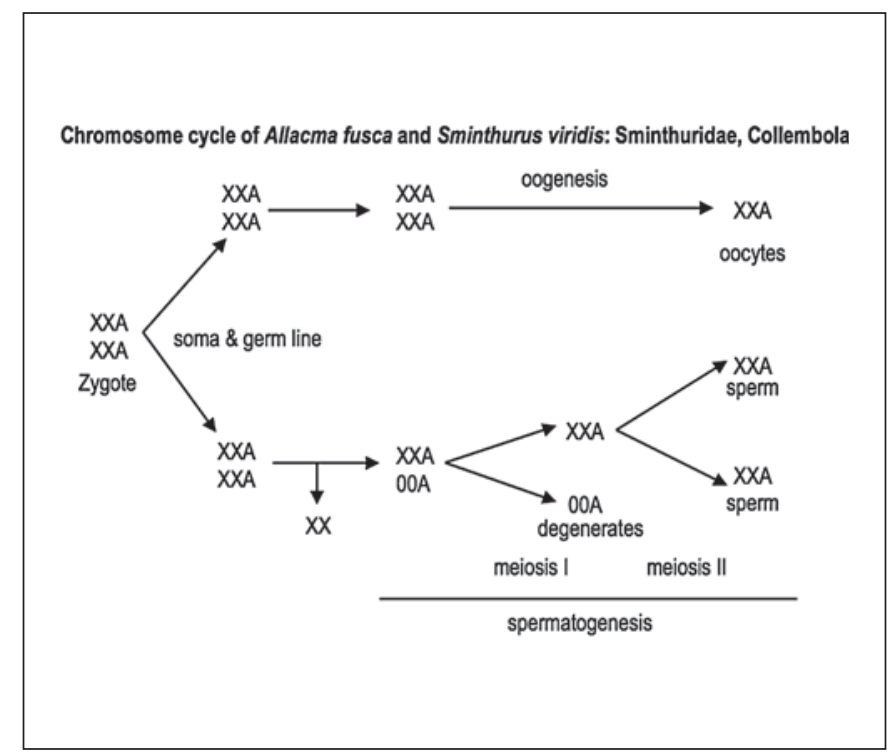

Fig. 3. The chromosomal cycle of Collembola species. X and A refer to sexual and autosomal chromosomes, respectively. Modified from Dallai et al. [2000].

erate, whereas the XX spermatocytes follow a normal second meiotic division, giving rise to $2 \mathrm{XX}$ sperm. The paternal origin of the eliminated $\mathrm{X}$ chromosomes and thus if an imprinting process occurs in these insects or not remain unknown. Notwithstanding, the Sciaridae models outlined above could apply to the Collembola chromosome cycle in relation to sex determination.

\section{Sex Determination Mechanisms Based on Elimination or Heterochromatinization of Chromosomes: The Coccid System}

Sex determination in primitive coccids is usually decided by the XX (female)/X0 (male) sex chromosome mechanism. However, in some groups, the sex of an individual is not fixed at fertilization, as in the Sciaridae, Cecydomyiidae and Collembola insects mentioned above. Sex determination in the coccids follows the haploid (male) and diploid (female) mechanism that results from the differential inactivation and/or elimination of chromosomes [Brown and Nur, 1964; White, 1973; Brown and Chandra, 1977; Miller and Kosztarab, 1979; Herrick and Seger, 1999]. Among the different sexual chromosome systems found in the coccids, the 2 most paradigmatic are shown in figure 4.

Imprinting and Sex Determination

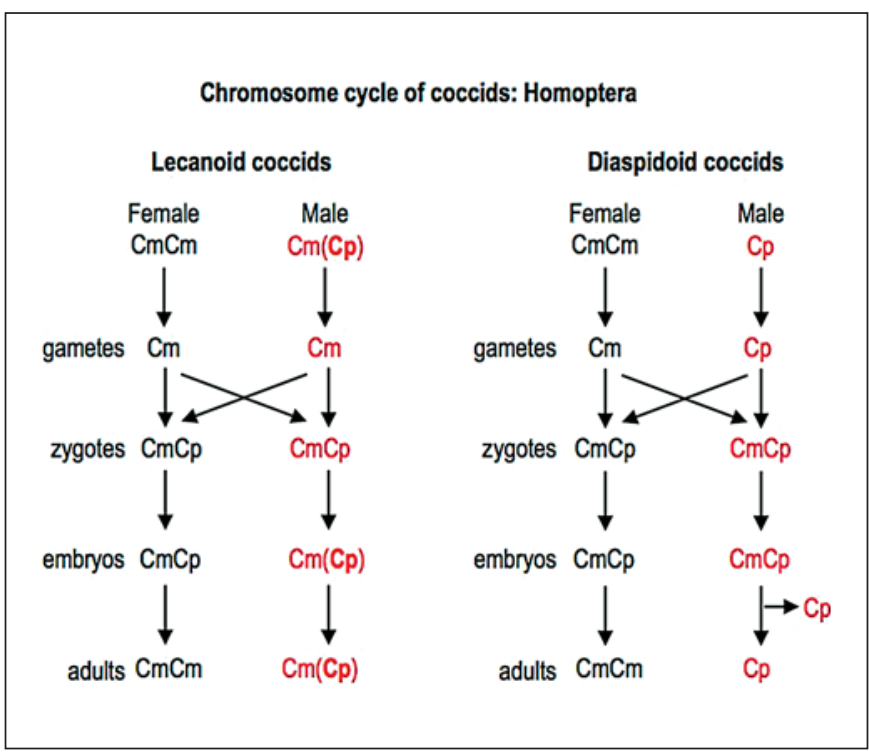

Fig. 4. The chromosomal cycle of coccid species. $\mathrm{Cm}$ and $\mathrm{Cp}$ refer to the maternally and paternally derived chromosome complements, respectively. (Cp) stands for the heterochromatic (inactivation) state of the Cp complement. Modified from Sánchez [2008].

The lecanoid system is based on a functional haploidy/ diploidy mechanism. All the chromosomes of the zygote are euchromatic. The embryos in which the chromosome set inherited from the father becomes heterochromatic (inactivated) will develop as males, whereas the embryos in which all chromosomes remain euchromatic (functional) will develop as females. This decision occurs at the cleavage stages during embryogenesis. Therefore, the females are functionally diploid, and males are structurally diploid but functionally haploid. Oogenesis is orthodox, whereas spermatogenesis is characterized by an inverse meiosis and the lack of chromosome pairing and genetic recombination. The first meiotic division is equatorial (disjunction of the sister chromatids), while the second is reductional (disjunction of the maternal and paternal homologs). The result is the formation of the expected 4 nuclei, 2 of which are euchromatic and 2 of which are heterochromatic. Only the euchromatic nuclei undergo spermiogenesis to form functional sperm, so that they carry the maternally inherited chromosomes. The heterochromatic nuclei do not form sperm and disintegrate.

The diaspidoid system is also based on a haploid/diploid mechanism. It differs from the lecanoid system in that the chromosome complement inherited from the father is eliminated, instead of being inactivated by heterochromatinization. Hence, the males are structurally and 
therefore functionally haploid. Oogenesis is orthodox. Spermatogenesis, however, is unorthodox since the paternal chromosomes are absent, and the second meiotic division does not occur. Sperm cells carrying a set of the maternal chromatids are therefore produced.

The Comstockiella have a similar mechanism to the lecanoid one. It differs in that one chromosome of the heterochromatic set remains heterochromatic during spermatogenesis; the remainder of the heterochromatic set is eliminated before prophase. This single heterochromatic chromosome is later eliminated so that the sperm only transmit maternal chromosomes [Brown, 1977; Miller and Kosztarab, 1979; Herrick and Seger, 1999].

The following summarizes some features of the lecanoid and diaspidoid mechanisms relevant to sex determination [for further details, see Brown and Nur, 1964; White, 1973; Brown and Chandra, 1977; Miller and Kosztarab, 1979; Herrick and Seger, 1999]:

(1) Coccid chromosomes are holocentric. After irradiation of either male or female parents, all of the paternal and maternal chromosome fragments are, respectively, heterochromatic and euchromatic. Therefore, there cannot be a single locus or restricted region on each chromosome that regulates the induction of heterochromatinization [Brown and Nelson-Rees, 1961; Nur, 1990].

(2) The sex ratio of the offspring of female coccids can fluctuate widely and is subject to environmental influences [Nelson-Rees, 1960]. Aging the females before allowing them to mate alters the sex ratio in favor of males, which is not due to a differential increase in the mortality of female zygotes. Rather, it is explained by changes in sexual dichronism (i.e. the deposition of male and female embryos at different times during oviposition), the pattern of which can be altered by maternal aging [James, 1937, 1938; Brown and Bennett, 1957; Nelson-Rees, 1960].

(3) Some parthenogenic coccids are known to produce male or female embryos depending upon whether or not the heterochromatinization of 1 chromosomal set occurs. Since heterochromatinization naturally occurs in these coccids, no prior passage of the chromosomes through spermatogenesis is required [Nur, 1963].

These results suggest that the genome of the mother determines the heterochromatinization (lecanoid) or elimination (diaspidoid) of the paternally inherited chromosomes in coccid embryos. In addition, both the lecanoid and diaspidoid mechanisms have an associated imprinting process to distinguish between the maternal and paternal chromosomes. This chromosome behavior is similar to that seen with respect to the elimination of paternal X chromosomes in sciarid flies. It has been proposed that the model for the control of differential $\mathrm{X}$ chromosome elimination in the sciarids mentioned above can be applied to the heterochromatinization or elimination of paternal chromosomes in coccids [Sánchez, 2008]. According to this model, heterochromatinization or elimination is controlled by a MF, with the maternally derived chromosomes imprinted so that they do not suffer either fate.

In primitive coccids, gender is determined by the conventional XX/X0 system and in more evolved coccids lecanoids, comstockiellids and diaspidoids - on a haploid/diploid system. It appears that the evolutionary sequence is lecanoid-comstockiellid-diaspidoid [Brown and McKenzie, 1962; Haig, 1993a; Herrick and Seger, 1999]. If the sex-determining mechanism of primitive coccids was not working with the haploid/diploid strategy evolved in the lecanoid/diaspidoid coccids, a new primary genetic signal had to evolve. Alternatively, the primary genetic signal that determines gender in both primitive and lecanoid/diaspidoid coccids could be the same. In this case, during the evolution of the lecanoid/diaspidoid systems, the only thing that changed was the appearance of a mechanism that brings about either diploidy or haploidy - whether structural or functional - of the embryo; the primary zygotic genetic signal determining gender in the primitive coccids would remain the same. To this respect, the only primary sex-determining signal compatible with the XX/X0 system of primitive coccids and the haploid/diploid system of more evolved lecanoid/ diaspidoid coccids is that in which gender depends on the number of copies of an X-linked gene [for a detailed discussion, see Sánchez, 2008].

\section{The Maternal Effect Genomic Imprinting Sex Determination-Model}

Maternal imprinting appears to be also involved in sex determination mechanisms that are not based on elimination or inactivation of chromosomes, as described above, but it affects the expression of single genes. Beukeboom et al. [2007] proposed the so-called maternal effect genomic imprinting sex determination-model to explain sex determination in the parasitoid hymenopteran Nasonia vitripennis. In brief, this model proposes that the sex of the zygote depends on the activity of the $z y$ gotic sex determiner ( $z s d$ ) gene, whose function determines female development. A maternal effect gene ( $m s d$ ) causes imprinting of the $z s d$ gene during oogenesis so 
that the female-inherited $z s d$ allele is not active in the zygote. Consequently, haploid zygotes develop as males because they carry the imprinted $z s d$ allele inherited from the mother. Diploid zygotes develop as females because the paternally inherited $z s d$ is not imprinted and then becomes expressed [ $\mathrm{Ma}$ et al., this issue]. Whether or not there are mechanistic similarities and similar genes involved in this form of sex determination and sex determination by chromosome elimination remains to be seen.

\section{Imprinting: General Considerations}

Three main features characterize the imprinting process:

(1) It is a sex- and a germ-line-specific process; imprinting occurs during gametogenesis in 1 of the 2 sexes. The establishment of imprinting is the result of a 2-step process. There must be a 'signal' determining its specificity (first step) that triggers the formation (second step) of the 'imprinting mark'.

(2) The imprinted state is maintained during development; it is passed from a cell to its 2 daughter cells in each cell division.

(3) The imprinted state is reversible; the imprinting mark is erased in the following generation, during the gametogenesis process in the opposite sex where imprinting occurs.

Nothing is known about the molecular nature of the 'imprinting signal'. However, during the last years, knowledge on the molecular basis of the imprinting mark' revealed that this is mainly formed by modifications at the DNA and/or chromosomal levels. The main DNA modification associated with imprinting is methylation; in particular, 5-methylcytosine methylation of CpG islands. At the chromosomal level, imprinting is predominantly associated with histone modification, mainly acetylation, methylation and phosphorylation, resulting in a chromatin conformation that promotes gene inactivation or the formation of facultative heterochromatin. Noncoding RNAs and RNAi have been also involved in imprinting.

These features can be applied to imprinting affecting the entire chromosomes or even the haploid sets of chromosomes, as described above. In what follows, the modifications affecting differently the maternal and paternal chromosomes in relation with sex determination will be reviewed.

Imprinting and Sex Determination

\section{Imprinting in Sciara: Modifications That Differently Affect Maternal and Paternal Chromosomes}

In sciarids, imprinting is intimately linked to the sex determination process, being associated with the elimination of chromosomes in the somatic cells and germ line cells. There are 3 elimination processes in sciarids: elimination of 1 or 2 paternal $X$ chromosomes from the nuclei that will form the somatic cells during the preblastoderm stage, elimination of 1 paternal X chromosome from the germ cells during embryogenesis and the elimination of the whole paternal haploid set of chromosomes during spermatogenesis. The histone modifications that have been observed in the maternal and paternal chromosomes of sciarids are summarized in table 1.

\section{Elimination of X Chromosomes in Somatic Cells}

Briefly, the zygote starts with $3 \mathrm{X}$ chromosomes; 2 of them are isochromosomes of paternal origin corresponding to the 2 chromatids of the maternally inherited $\mathrm{X}$ chromosome. In monogenic species, such as S. coprophi$l a$, all $\mathrm{L}$ chromosomes are the first being eliminated in both sexes during 5 th-6th nuclear cleavage divisions. The paternal X chromosomes are eliminated later, during the 7th-9th nuclear cleavage divisions. Elimination in females occurs preferentially in the 9th division. In digenic species, such as $S$. ocellaris, lacking $\mathrm{L}$ chromosomes, the paternal X chromosomes are mainly eliminated during the 9th nuclear cleavage division [reviewed in Goday and Esteban, 2001].

It was initially described that the eliminated $\mathrm{X}$ chromosomes separate more slowly than the rest of the chromosomes during anaphase and that the 2 chromatids never achieved complete separation. This led to the proposal that the elimination was a consequence of the centromeres being affected [Du Bois, 1933]. More recently, however, de Saint-Phalle and Sullivan [1996] analyzed X chromosome elimination in $S$. coprophila by using confocal microscopy and FISH methodology and concluded that the centromeres of the eliminated $\mathrm{X}$ chromosome remain active during anaphase. Therefore, the elimination is caused by a failure of the $\mathrm{X}$ chromatids to separate each other. These authors proposed that elimination was determined by alteration of the proteolytic machinery that acts for chromatid separation during anaphase.

Acetylation of histones $\mathrm{H} 3$ and $\mathrm{H} 4$ has been studied in somatic cells of early Sciara embryos. The first somatic chromosomes (following chromatin organization after fertilization) showed high acetylation in $\mathrm{H} 3$ at lysine 9 (H3K9Ac) and lysine14 (H3K14Ac) and in histone H4 
Table 1. Summary of histone modifications affecting maternal and paternal chromosomes of Sciara during chromosome elimination

\begin{tabular}{|c|c|c|}
\hline Developmental stage & Maternally derived chromosomes & Paternally derived chromosomes \\
\hline $\begin{array}{l}\text { Elimination of } 1 \text { or } 2 \mathrm{Xp} \\
\text { chromosomes in embryonic } \\
\text { somatic cells }\end{array}$ & $\begin{array}{l}\text { acetylated: H3K9Ac, H3K14Ac, H4K8Ac, } \\
\text { H4K12Ac }\end{array}$ & $\begin{array}{l}\text { acetylated: H3K9Ac, H3K14Ac, H4K8Ac, } \\
\text { H4K12Ac }\end{array}$ \\
\hline $\begin{array}{l}\text { Elimination of } 1 \text { paternal } \mathrm{X} \\
\text { chromosome from embryonic } \\
\text { germ cells during the 'resting stage' }\end{array}$ & $\begin{array}{l}\text { hypoacetylated: H3K9Ac, H3K14Ac, H4K8Ac, } \\
\text { H4K12Ac; } \\
\text { methylated: H3K4Me2, H3K4Me3 }\end{array}$ & $\begin{array}{l}\text { acetylated: } \mathrm{H} 3 \mathrm{~K} 9 \mathrm{Ac}, \mathrm{H} 3 \mathrm{~K} 14 \mathrm{Ac}, \mathrm{H} 4 \mathrm{~K} 8 \mathrm{Ac} \text {, } \\
\mathrm{H} 4 \mathrm{~K} 12 \mathrm{Ac} \text {, but the eliminated } \mathrm{Xp} \text { is } \\
\text { hypoacetylated; } \\
\text { hypomethylated: } \mathrm{H} 3 \mathrm{~K} 4 \mathrm{Me} 2, \mathrm{H} 3 \mathrm{~K} 4 \mathrm{Me} 3 \text {, } \\
\text { except the eliminated Xp }\end{array}$ \\
\hline $\begin{array}{l}\text { First meiotic division during } \\
\text { spermatogenesis }\end{array}$ & $\begin{array}{l}\text { acetylated: H3K9Ac, H3K14Ac, H4K8Ac, } \\
\text { H4K12Ac; } \\
\text { at prophase: } \\
\text { phosphorylated: H3S10P, H3S28P, H3T3P, } \\
\text { H3T11P; } \\
\text { during anaphase: } \\
\text { unphosphorylated: H3S10P, H3S28P, H3T3P, } \\
\text { H3T11P }\end{array}$ & $\begin{array}{l}\text { hypoacetylated: H3K9Ac, H3K14Ac, } \\
\text { H4K8Ac, H4K12Ac } \\
\text { at prophase: } \\
\text { phosphorylated: H3S10P, H3S28P, H3T3P, } \\
\text { H3T11P } \\
\text { during anaphase: } \\
\text { phosphorylated: H3S10P, H3S28P, H3T3P, } \\
\text { H3T11P }\end{array}$ \\
\hline $\begin{array}{l}\text { Second meiotic division during } \\
\text { spermatogenesis }\end{array}$ & $\begin{array}{l}\text { phosphorylated: autosomal maternal } \\
\text { chromosomes with H3S10P, H3S28P, H3T3P, } \\
\text { H3T11P until complete separation of } \\
\text { chromatids; maternal X chromosome with } \\
\text { H3S10P, H3S28P, H3T3P, H3T11P except } \\
\text { in the centromere }\end{array}$ & discarded into the cytoplasmic bud \\
\hline
\end{tabular}

$\mathrm{Xp}=$ Paternally inherited $\mathrm{X}$ chromosome; acetylation of histone $\mathrm{H} 3$ and $\mathrm{H} 4$ : H3K9Ac = acetylated histone $\mathrm{H} 3$ on lysine 9, $\mathrm{H} 3 \mathrm{~K} 14 \mathrm{Ac}=$ acetylated histone $\mathrm{H} 3$ on lysine $14, \mathrm{H} 4 \mathrm{~K} 8 \mathrm{Ac}=$ acetylated histone $\mathrm{H} 4$ on lysine $8, \mathrm{H} 4 \mathrm{~K} 12 \mathrm{Ac}=$ acetylated histone $\mathrm{H} 4$ on lysine 12; phosphorylation of histone $\mathrm{H} 3$ : H3S10P = phosphory- lated histone $\mathrm{H} 3$ on serine $10, \mathrm{H} 3 \mathrm{~S} 28 \mathrm{P}$ = phosphorylated histone $\mathrm{H} 3$ on serine $28, \mathrm{H} 3 \mathrm{~T} 3 \mathrm{P}$ = phosphorylated histone $\mathrm{H} 3$ on threonine $3, \mathrm{H} 3 \mathrm{~T} 11 \mathrm{P}=$ phosphorylated histone $\mathrm{H} 3$ on threonine 11; methylation of histone $\mathrm{H} 3$ : $\mathrm{H} 3 \mathrm{~K} 4 \mathrm{Me} 2$ = dimethylated histone $\mathrm{H} 3$ on lysine $4, \mathrm{H} 3 \mathrm{~K} 4 \mathrm{Me} 3$ = trimethylated histone $\mathrm{H} 3$ on lysine 4 . at lysine 8 (H4K8Ac) and lysine 12 (H4K12Ac). Furthermore, this acetylation pattern was homogeneous in the interphase nuclei during the nuclear cleavage divisions, suggesting that no significant differences in $\mathrm{H} 3$ and $\mathrm{H} 4$ acetylation occur between maternal and paternal chromosomes [Goday and Ruiz, 2002].

\section{Elimination of One X Chromosome in Embryonic Germ Cells}

During the nuclear cleavage stage, when the nuclei migrate to the cortex of the egg, 2 of the nuclei that move towards the posterior and enter the pole plasma will form the germ cells, which remain with the zygotic XXX chromosome constitution. These germ cells subsequently will travel to the gonad site, where they remain undivided until the beginning of the second larval instar. This period is known as the 'resting stage' [reviewed in Goday and Esteban, 2001]. It is during this period when 1 paternal
$\mathrm{X}$ chromosome is simultaneously eliminated from the germ cells in both sexes so that these cells become now $\mathrm{XX}$ cells. The paternal X chromosome is expelled from the nuclei through a mechanism not well understood that involves the nuclear membrane [Berry, 1939, 1941; Perondini and Ribeiro, 1997]. Since the 2 paternally inherited X chromosomes are isochromosomes, the question arises what determines which of the 2 will be eliminated. In other words, is there any difference between the $2 \mathrm{X}$ chromosomes at the time when the elimination occurs? It has been observed that the future-eliminated $\mathrm{X}$ chromosome seems to be slightly more condensed than the other chromosomes, and in addition, it is intimately attached to the nuclear membrane [Perondini and Ribeiro, 1997].

More recently, acetylation and methylation patterns of histones have been studied in germ cells during the resting stage and until gonadal mitotic divisions are initiated. The 
paternal chromosomes presented higher levels of modified histones H3K9Ac, H3K14Ac, H4K8Ac, and H4K12Ac than maternal chromosomes in both S. ocellaris and S. coprophila [Goday and Ruiz, 2002]. Very interestingly, the X chromosome that will be excluded from the germ cells during the resting stage did not appear to have significant levels of $\mathrm{H} 3 / \mathrm{H} 4$ acetylation, in contrast to the other paternal chromosomes including the second paternal X chromosome [Goday and Ruiz, 2002]. These results led Goday and Ruiz [2002] to propose that this different degree of acetylation might constitute a signal to determine which of the 2 paternal $\mathrm{X}$ chromosomes will be eliminated in the embryonic germ cells: the lower degree of acetylation might be required for the eliminated $\mathrm{X}$ chromosome to interact with the inner nuclear membrane. The same mechanism for the elimination of 1 paternal X chromosome appears to be also involved in the elimination of $\mathrm{L}$ chromosomes in S. coprophila germ cells, with these chromosomes also being hypoacetylated [Goday and Ruiz, 2002]. At later larval stages, preceding the initiation of mitotic gonadal divisions, all chromosomes of the germ line exhibited similar levels of histone $\mathrm{H} 3 / \mathrm{H} 4$ acetylation [Goday and Ruiz, 2002].

In S. ocellaris, germ cells during the early embryonic development and during the 'resting stage' showed high levels of dimethylated $(\mathrm{H} 3 \mathrm{~K} 4 \mathrm{Me} 2)$ and trimethylated (H3K4Me3) forms of histone $\mathrm{H} 3$ at lysine 4 in the maternally derived chromosomes and in the paternal X chromosome that becomes eliminated, whereas the rest of the paternally derived chromosomes including the second paternal X chromosome did not show significant levels of methylation [Greciano and Goday, 2006]. This different degree of methylation, like in the case of acetylation, might also contribute to the specification by which the paternal X chromosome is eliminated from the germ cells during the 'resting stage' [Greciano and Goday, 2006].

\section{Elimination of Paternal Chromosomes during Spermatogenesis}

During the first meiotic division, when the whole paternal chromosomal set is eliminated in both $S$. ocellaris and S. coprophila, the acetylation pattern is the reverse of that seen in early germ cells; namely, the whole paternal chromosomal set is now hypoacetylated for H3K9Ac, H3K14Ac, H4K8Ac, and H4K12Ac, whereas the maternal chromosomal set is acetylated [Goday and Ruiz, 2002]. In addition, the L chromosomes are also hypoacetylated [Goday and Ruiz, 2002]. During the second meiotic division, weak and irregular acetylation of the maternally inherited chromosomes was reported [Goday and Ruiz, 2002]. Dur-

Imprinting and Sex Determination ing spermiogenesis, round and elongated spermatids showed nuclear staining for acetylated $\mathrm{H} 3$ and $\mathrm{H} 4$ [Goday and Ruiz, 2002]. All these results led to the hypothesis that elimination of chromosomes in the germ cells of Sciara might require that these chromosomes are hypoacetylated for histones H3 and H4 [Goday and Ruiz, 2002].

Recently, a new study of male meiosis has been performed by immunostaining analyses regarding the location and the timing distribution of modified histone $\mathrm{H} 3$ phosphorylated at $4 \mathrm{~N}$-terminal residues: phosphorylated histone $\mathrm{H} 3$ on serine $10(\mathrm{H} 3 \mathrm{~S} 10 \mathrm{P})$, phosphorylated histone $\mathrm{H} 3$ on serine 28 (H3S28P), phosphorylated histone $\mathrm{H} 3$ on threonine 3 (H3T3P), and phosphorylated histone H3 on threonine 11 (H3T11P) [Escribá et al., 2011a].

In S. ocellaris, at the prophase stage of the first meiotic division, both paternal and maternal chromosomal sets presented similar substantial degrees of $\mathrm{H} 3$ phosphorylation and condensation. Later, during the anaphase-like stage, the paternal, but not the maternal chromosomal sets showed high levels of H3S10P and H3S28P phosphorylation, which positively correlates with the degree of chromatin condensation. Thus, in the transition from prophase to anaphase, the paternal chromosomes remained phosphorylated and condensed, whereas the maternal chromosomes, which are associated with the polar complex, become decondensed and $\mathrm{H} 3$ dephosphorylated [Escribá et al., 2011a].

The second meiotic division of spermatogenesis is orthodox except for the behavior of the maternal inherited $\mathrm{X}$ chromosome, which does not move to the equatorial plate but remains with the polar complex formed during the first meiotic division [Metz, 1925; Crouse, 1943; Goday and Esteban, 2001]. The transition from first to second meiotic division is characterized by a significant $\mathrm{H} 3$ phosphorylation of the maternal autosomes located in the metaphase plate (at this stage, the paternal chromosomes have been already lost in the cytoplasmic bud). $\mathrm{H} 3$ phosphorylation persists during anaphase until the sister chromatids of these autosomes are completely separated. Subsequently, $\mathrm{H} 3$ phosphorylation starts to decline in a progressive way from the centromere towards telomeres. Interestingly, the maternal $\mathrm{X}$ chromosome, which remained associated to the polar complex of the first meiotic division, is also $\mathrm{H} 3$ phosphorylated except in the centromere region, and during the anaphase of second meiotic division, it shows a progressive dephosphorylation towards the telomeres. In male meiosis of S. coprophila, which carries $\mathrm{L}$ chromosomes, the $\mathrm{H} 3$ phosphorylation pattern mimics that of $S$. ocellaris, not only for ordinary but also for L chromosomes [Escribá et al., 2011a]. 
The X Chromosome Controlling Element

Work done on the control of X chromosome elimination during spermatogenesis in S. coprophila identified a cis-acting locus, named the 'controlling element' (CE), in the $\mathrm{X}$ chromosome region containing 3 heterochromatic blocks proximal to the centromere [Crouse, 1960a, b; Gerbi, 1986]. The analysis of translocations between the $\mathrm{X}$ chromosome and autosomes involving the $\mathrm{CE}$ revealed that the presence of this element in an autosome causes its elimination, even when CE is located far from the centromere of the autosome [Crouse, 1979], suggesting that this element controls the function of the centromere in the X chromosome [Gerbi, 1986]. The molecular nature of CEs and how this exerts its function on the X centromere remain unknown. Nevertheless, the results of Escribá et al. [2011a] on the lack of histone H3 phosphorylation in the centromere of the maternal X chromosome during spermatogenesis led these authors to hypothesize that the CE might affect the function of this centromere by preventing its phosphorylation with the consequent nondisjunction of the $2 \mathrm{X}$ chromatids.

\section{Intranuclear Clustering of Chromosomes of the Same} Parental Origin

Cytological analysis in S. coprophila revealed that paternal and maternal chromosomal sets form 2 separated aggregates in male germ cells during meiosis [Rieffel and Crouse, 1966; Kubai, 1982, 1987; Goday and Ruiz, 2002]. It has been suggested that this chromosome compartmentalization may be already established in premeiotic germ cells allowing the nonrandom chromosome segregation and the corresponding elimination of the paternal set during the first meiotic division [Kubai, 1987]. On the other hand, a sort of compartmentalization has been also described for the activity of the histone acetyltransferases and histones deacetylases, which appear to be localized in discrete nuclear regions [Kruhlak et al., 2001]. These results together with the observed differences in the degree of acetylation in histones $\mathrm{H} 3$ and $\mathrm{H} 4$ for the sciarid chromosomal sets, depending on their parental origin, led Goday and Ruiz [2002] to propose a model that integrates acetylation of $\mathrm{H} 3$ and $\mathrm{H} 4$, intranuclear clustering of chromosomes depending on their parental origin and chromosome elimination in Sciara germ cells during the 'resting stage' and during the first male meiotic division. This model proposes that histone acetylation levels and a specific intranuclear arrangement of chromosomes might be linked; distinct histone acetylation levels between maternal and paternal chromosomal sets are the result of their different nuclear localization and the localized distribution of acetyltransferases and histone deacetylases. This proposal would imply that chromosome location within the nucleus of germ cells is a key component of the imprinting process related to chromosome elimination in Sciara.

\section{Imprinting in Coccids: Modifications That Differentially Affect the Maternal and Paternal Chromosomes}

In coccids, imprinting is also intimately linked to the sex determination process, which is associated with the inactivation (lecanoid mechanism) or the elimination (diaspidoid mechanism) of the whole chromosomal set inherited from the father. Different from the sciarids, in the coccids, the inactivation/elimination of all paternal chromosomes affects both somatic and germ cells, so that both tissues have the same chromosome constitution. Much of the work about imprinting on coccids has been done with Planococcus citri (mealybug), which belongs to the lecanoid mechanism of sex determination. Investigation of the molecular basis underlying imprinting has been mainly focused on DNA methylation, specifically 5 -methylcytosine methylation, and on proteins such as heterchromatin protein (HP1) and histone modifications that determine the chromatin structure [reviewed in Sha, 2008; Macdonald, 2012]. The modifications associated with the maternal and paternal chromosomes are summarized in table 2 .

\section{DNA Methylation of Maternal and Paternal \\ Chromosomes in Coccids}

In coccids, the existence of methylated-cytosine DNA [Achwal et al., 1983] and of cytosine-specific DNA methyltransferases has been demonstrated [Devajyothi and Brahmachari, 1992]. Bongiorni et al. [1999] analyzed the methylation pattern of maternal and paternal chromosomes at the chromosomal level in $P$. citri with the restriction enzymes HpaII and MspI. These 2 isoschizomers recognize the same restriction DNA sequence but have a different effect: HpaII does not cut the DNA when the cytosine in the restriction sequence is methylated, whereas MspI does. They reported differences in methylation between the maternal and paternal chromosomes, with the latter being hypomethylated. X-ray-irradiated males were used in the crosses with nonirradiated virgin females. Irradiation causes fragmentation of the chromosomes, which were not lost during spermatogenesis due to their holocentric feature. It was observed in the embryo that the chromosome fragments were the ones that pre- 
Table 2. Summary of modifications affecting maternal and paternal chromosomes in male coccids

\begin{tabular}{lll}
\hline Developmental stage & Maternally derived chromosomes & Paternally derived chromosomes \\
\hline Embryos & female gamete nucleus: none & male pronucleus: presence of H3K9Me3 and \\
& female pronucleus: none & H4K16Ac \\
elimination stage: methylated DNA & male pronucleus: none \\
& elimination stage: hypomethylated DNA & presence and colocalization of PCHET2, \\
& & H3K9Me3 and H4K20Me3 \\
& hypoacetylated: H4Ac
\end{tabular}

\begin{tabular}{|c|c|c|}
\hline Male gametogenesis & $\begin{array}{l}\text { spermatogonias: presence and colocalization of } \\
\text { H4K20Me3 and HP2-like } \\
\text { euchromatic spermatids: presence and } \\
\text { colocalization of H3K9Me2, H3K9Me3, PCHET2, } \\
\text { and HP2-like } \\
\text { no differences between the } 2 \text { euchromatic } \\
\text { spermatids for H3K9Me2, H3K9Me3 and HP2-like } \\
\text { sperm: presence of H3K9Me2, H3K9Me3 and } \\
\text { HP2-like }\end{array}$ & $\begin{array}{l}\text { spermatogonias: presence and colocalization of } \\
\text { PCHET2, H3K9Me2 and H3K9Me3 } \\
\text { heterochromatic spermatids: presence and } \\
\text { colocalization of } \mathrm{H} 3 \mathrm{~K} 9 \mathrm{Me} 2, \mathrm{H} 3 \mathrm{~K} 9 \mathrm{Me} 3 \text {, } \\
\text { PCHET2, and HP2-like } \\
\text { sperm: do not contain paternally inherited } \\
\text { chromosomes }\end{array}$ \\
\hline
\end{tabular}

$\mathrm{H} 4 \mathrm{~K} 16 \mathrm{Ac}=$ Acetylated histone $\mathrm{H} 4$ on lysine 16; H3K9Me2 = dimethylated histone $\mathrm{H} 3$ on lysine 9; H3K9Me3 = trimethylated histone $\mathrm{H} 3$ on lysine 9; PCHET2 = HP1-like protein of coccids.

sented hypomethylation, thus confirming that the hypomethylated chromosomal set was the one inherited from the father. Bongiorni et al. [1999] concluded that methylation of DNA is used as the 'imprinting mark' for embryonic facultative heterochromatinization of chromosomes after the 7th cleavage division, but not for heterochromatinization itself. The different methylation level between the maternal and paternal chromosomes would constitute the signal that the heterochromatinization machinery would recognize so that the hypomethylated paternal chromosomes become inactivated.

\section{HP1 in Maternal and Paternal Chromosomes in Coccids}

Contradictory results have been reported regarding HP1 and heterochromatinization of paternal chromosomes in mealybug males. The genes encoding HP1 have been characterized in P. citri: 2 sequences were identified, pchet 1 and pchet 2 , encoding the putative coccid HP1 (PCHET1) and HP2 (PCHET2) proteins [Epstein et al., 1992]. The authors produced a polyclonal antibody against PCHET1. This protein was only present in males, but no correlation appeared to exist between the localization of the protein and the heterochromatic chromosomes in the mealybug males.

Bongiorni et al. [2001] reported a different result regarding the localization of the HP1 in mealybug males and females. They used a monoclonal antibody against the Drosophila HP1 protein that recognizes the ortholog HP1-like protein in the coccids. They found that the HP1 antibody specifically stained the paternal, but not the maternal chromosomes in males. In females, however, the HP1 antibody showed a dispersed distribution in both euchromatin and constitutive heterochromatin. Interestingly, there is a correlation between the presence of HP1like in the paternal chromosomes and their heterochromatic state. In mealybugs, the paternally inherited chromosomal set starts to become inactivated (facultative heterochromatinization) after the 7th cleavage division [Bongiorni et al., 2001]. In male embryos, HP1-like concentrates in discrete spots on the paternal chromosomes before heterochromatinization, and later, HP1-like is vastly distributed along the whole chromosomes when these become heterochromatic [Bongiorni et al., 2001]. The authors concluded that binding of HP1-like to the paternal chromosomes caused their heterochromatinization, which is in agreement with the observation that HP1-like is required in mealybugs for the inactivation of the paternal chromosome complement.

\section{Histone Modifications in Maternal and Paternal Chromosomes in Coccids}

It has been shown in mammals that the interaction between HP1 and histone H3 trimethylated on lysine 9 
(H3K9Me3) and histone $\mathrm{H} 4$ trimethylated on lysine 20 (H4K20Me3) is essential for the chromatin to acquire the conformation causing gene silencing [reviewed in Macdonald, 2012].

Studies on the distribution of HP1-like, H3K9Me3 and H4K20Me3 in mealybugs showed that HP1-like and the 2 methylated histones colocalized and were specifically associated with the paternal chromosomes in males [Bongiorni et al., 2001, 2007; Cowell et al., 2002; Kourmouli et al., 2004]. Remarkably, the elimination of HP1-like affected heterochromatinization of the mealybug paternal chromosomes. By using dsRNAi methodology, Bongiorni et al. [2007] interfered the expression of the gene pchet 2 encoding the HP1-like protein PCHET2 in mealybug. When this interference was done in male embryos undergoing facultative heterochromatinization, the staining of the paternal chromosomes with the corresponding antibodies for HP1like, H3K9Me3 and H4K20Me3 was lost, together with the lack of heterochromatinization. These data support the involvement of HP1-like, H3K9Me3 and H4K20Me3 in the heterochromatinization of paternal chromosomes in male mealybugs and confirm, in addition, that the gene pchet 2 encodes the HP1-like protein PCHET2 in mealybugs.

The other modification of histones involved in chromatin structure is acetylation [Macdonald, 2012]. Studies on acetylated histone $\mathrm{H} 4(\mathrm{H} 4 \mathrm{Ac})$ revealed that the heterochromatic (inactivated) paternal chromosomes of mealybug males are hypoacetylated with respect to the nonheterochromatic (active) maternal chromosomes [Ferraro et al., 2001].

Contradictory results have been reported regarding the analysis of HP1-like, H3K9Me3 and H4K20Me3 during male and female gametogenesis in mealybugs. Buglia and Ferraro [2004] reported that the 2 functional sperms from each male meiotic event showed different levels of both HP1 and H3K9Me3. They postulated that those differences constitute the 'imprinting mark' (paternal imprinting) related to the heterochromatinization of the paternal chromosomes in male embryos: the chromosomes showing higher levels of HP1 and H3K9Me3 would be 'imprinted' to become heterochromatinized by the recruitment of additional cytoplasmic factors supplied by the oocyte.

The presence of H3K9Me2, H3K9Me3, H4K20Me3, PCHET2, and HP2-like protein [Volpi et al., 2007] has been analyzed during male and female gametogenesis [Bongiorni et al., 2009]. The 5 proteins were present at all stages, but their distribution patterns vary depending on the spermatogenic stage: spermatogonias presented colocalized H3K9Me2, H3K9Me3 and PCHET2 in the hetero- chromatic paternal chromosomes, and H4K20Me3 and HP2-like colocalized in the euchromatic maternal chromosomes. At the spermatid stage, H3K9Me2, H3K9Me3, PCHET2, and HP2-like were found in both heterochromatic spermatids (containing the paternal chromosomes) and euchromatic spermatids (containing the maternal chromosomes), and no differences were observed for H3K9Me3, HEK9Me2 and HP2-like between the 2 spermforming euchromatic spermatids. Sperms exhibited H3K9Me2, H3K9Me3 and HP2-like, but not PCHET2. The presence of these proteins was also studied in the male and female pronuclei following fertilization of the oocyte by the sperm at 2 stages: during progression and completion of the second female meiotic division and during the restructuring of both the male and female gamete nuclei into the male and female pronuclei, respectively, before they become fused to form the diploid zygotic nucleus. In addition, the presence of histone $\mathrm{H} 4$ acetylated on lysine 16 (H4K16Ac) was also monitored, as an indicator for decondensation of the male pronuclei that takes place during progression and completion of the second female meiotic division [Adenot et al., 1997]. H4K20Me3, PCHET2 and HP2-like were detectable neither in female nor in male gamete nuclei and pronuclei, whereas $\mathrm{H} 4 \mathrm{~K} 16 \mathrm{Ac}$ was observed in the male pronucleus, and $\mathrm{H} 3 \mathrm{~K} 9 \mathrm{Me} 3$ was detected only at the earlier stage of decondensation. No presence of those modified histones and proteins were observed when the male and female pronuclei fused to form the zygotic nucleus. Thus, Bongiorni et al. [2009] failed to discover any difference in the 2 spermatozoids originated in each male meiotic event regarding the presence of HP1 and $\mathrm{H} 3 \mathrm{~K} 9 \mathrm{Me} 3$ reported by Buglia and Ferraro [2004]. Very interestingly, none of the modified histones as well as PCHET2 and HP2-like proteins analyzed in spermatogenesis were detected during oogenesis.

\section{Discrimination between Maternal and Paternal Imprinting: General Considerations}

The elimination/inactivation process of imprinted chromosomes in relation to sex determination involves 3 actors in the play (whatsoever their molecular nature): an elimination/inactivation factor that recognizes the imprinted mark in the imprinted chromosome either causing or preventing its elimination/inactivation and an imprinter factor that 'marks' the chromosome causing its imprinted state. The criterion to discriminate between maternal and paternal imprinting should be based on where the imprinter factor functions: if it functions dur- 


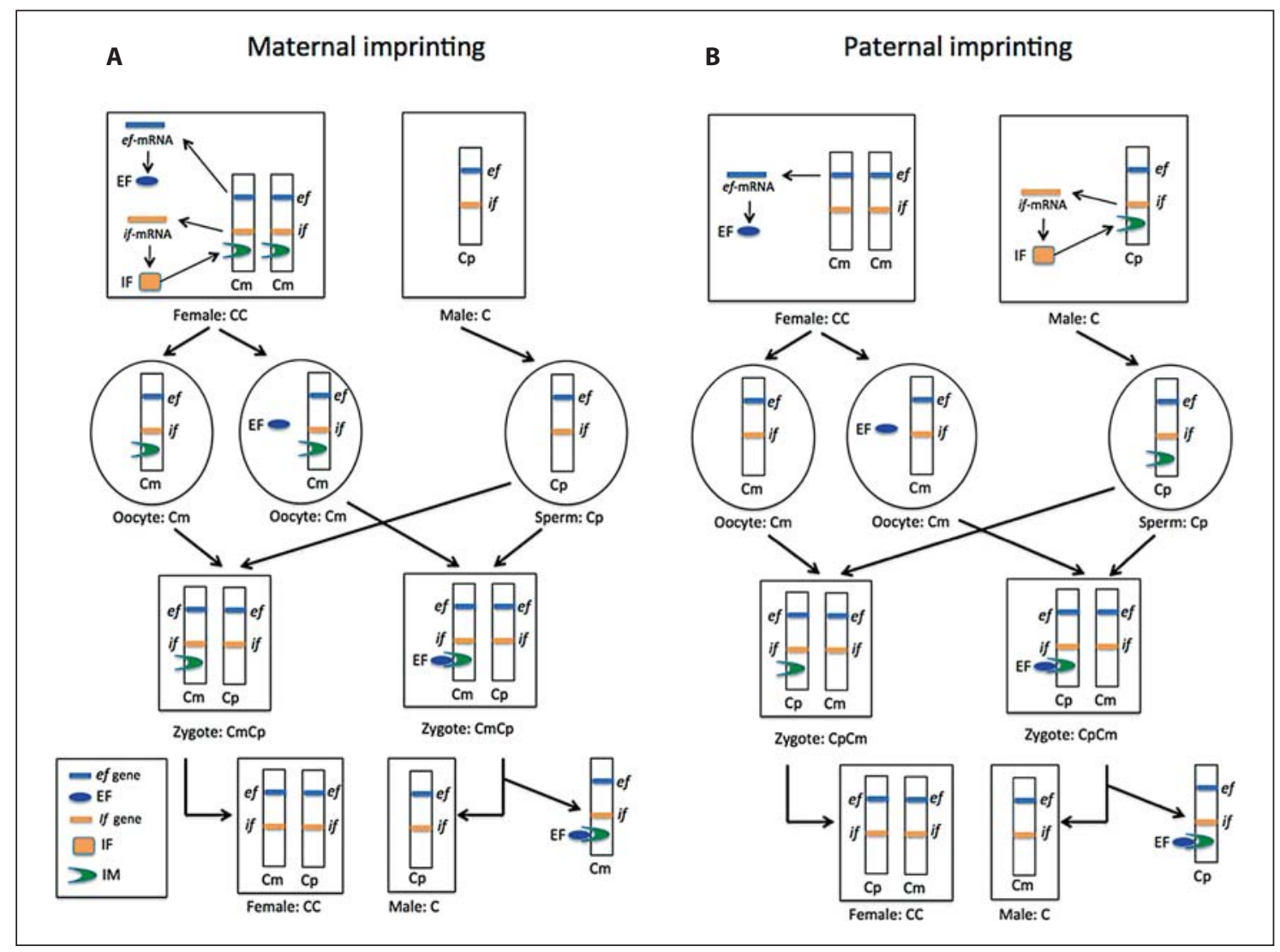

Fig. 5. Differences between maternal (A) and paternal (B) imprinting in relation to chromosome elimination. $\mathrm{Cm}$ and $\mathrm{Cp}$ stand for the maternal and the paternal chromosome set, respectively. It is assumed that females are diploid (CC) and males haploid (C). Furthermore, ef stands for the gene encoding the elimination factor (EF), which is specifically expressed in the female during oogenesis; it is assumed that only half of the oocytes received EF. More- over, if stands for the gene encoding the imprinter factor (IF), which acts specifically on the chromosomes to mark them with the imprinting mark (IM). See insets for further details. Notice that the gene if is specifically expressed during oogenesis in the case of maternal imprinting and is specifically expressed during spermatogenesis in case of paternal imprinting. In any case, imprinting is reversible in the next generation (see text). ing oogenesis, we speak of maternal imprinting, whereas if it functions during spermatogenesis, we speak of paternal imprinting.

Figure 5 presents a simple scheme showing the difference between maternal and paternal imprinting in relation to chromosome elimination, in the case in which the elimination factor promotes chromosome elimination, and imprinting is needed for that elimination. For simplification, there are sets of maternally and paternally derived chromosomes, respectively, and it is assumed that females are diploid and males haploid. Notice that the different effect between maternal and paternal imprinting depends on which of the 2 sexes expresses the imprinter factor. In case of maternal imprinting (fig. 5A), the gene encoding the imprinter factor is specifically expressed in the female during oogenesis, and this factor imprints the maternal chromosomes. In the case of paternal imprinting (fig. 5B), the imprinter factor gene is specifically expressed in males during spermatogenesis, and this factor imprints the paternal chromosomes. The elimination factor is exclusively produced in the female during oogenesis. In the zygote, this factor interacts specifically with the imprinting mark causing elimination of the chromosome. It is assumed that half of the oocytes receive the elimination factor and the other half do not. Hence, chromosome elimination takes place only in the zygotes derived from elimination-factor-bearing oocytes, which generate the males of the next generation, whereas the females derived from the oocytes lack the elimination factor. Notice that the males produced in the case of maternal imprinting are patroclinous, whereas those produced in case of paternal imprinting are matroclinous. 
The alternative situation to that described above is when the elimination factor interacts with the chromosomes causing their elimination, and the imprinting mark prevents that interaction so that imprinting is needed to prevent chromosome elimination; the chromosomes that are eliminated are those that were not imprinted. In this scenario, the result is the opposite of the scenario above: matroclinous males will be produced in case of maternal imprinting, while patroclinous males will be generated in case of paternal imprinting. The imprinted pattern of the chromosomes is the same in both scenarios, yet the effect which chromosomes will be eliminated and will not be propagated to the next generation is the opposite. Therefore, it is not possible to discriminate between maternal and paternal imprinting based solely on the identification of imprinted chromosome differences in the zygote. This discrimination can only be solved after identification of the sex where the imprinter factor functions to produce the imprinted state.

To this respect, it is pertinent to discuss the most studied lecanoid mechanism of the coccids, looking for imprinted marks on the paternal chromosomes being identified as those to be heterochromatinized. As previously described, differences in DNA methylation and modified histones were found in paternal versus maternal chromosomes that might constitute the imprinted marks. On the other hand, it was before indicated that evidences exist for a MF to participate in the specific heterochromatinization of paternal chromosomes. As an example, the distinct degree of DNA methylation in paternal versus maternal chromosomes will be used to discuss the logical considerations mentioned above. It is considered that the function of the MF is to carry out chromosome heterochromatinization so that the female produces 2 classes of oocytes either containing or lacking the MF: the first class will give rise to males, whereas the second class will produce females. Two possibilities exist regarding the interplay between the MF and the imprinting mark for chromosome heterochromatinization in the male embryos. In one case, the hypomethylated status of the paternal chromosomes constitutes the imprinted mark, which is recognized by the MF that triggers their heterochromatinization; and in the other case, the highly methylated status of the maternal chromosomes constitutes the imprinted mark that prevents their heterochromatinization by the MF. In the first case, the hypomethylated condition might be considered to reflect a decrease in the function of a DNA methyltransferase during spermatogenesis (paternal imprinting), compared to its normal function during oogenesis. Consequently, the imprinter factor that lowers the func- tion of the DNA methyltransferase would function in spermatogenesis, but not in oogenesis. It is because of this that we can speak of paternal imprinting. In the second case, in contrast, the highly methylated condition is considered to reflect an activation of the function of a DNA methyltransferase during oogenesis (maternal imprinting), compared to its basal function during spermatogenesis. Consequently, the imprinted factor that increases the function of the DNA methyltransferase would function in oogenesis, but not in spermatogenesis. It is because of this that we can speak of maternal imprinting. In conclusion, it is not possible to infer straightforward whether maternal or paternal imprinting exists in the coccids from the different degree of methylation shown by the paternal and the maternal chromosomes; therefore, we cannot discriminate between the 2 kinds of imprinting based solely on the identification of chromosome differences. The same applies to histone modifications affecting in a different way to maternal and paternal chromosomes.

From the conceptual point of view, further alternative scenarios can be visualized depending on the role played by the elimination/inactivation factor and the imprinted mark in the chromosome elimination/inactivation process. For explanation purposes, the elimination of the $\mathrm{X}$ chromosome in Sciara somatic cells will be used as a further example.

In Sciara, all zygotes start with the XXX chromosome constitution, 2 of which are inherited from the father. It is the elimination of either 1 or the 2 paternal X chromosomes what causes the final chromosome constitution XX or X0 that determines the female or male sexual development, respectively. In the case of Sciara, it has been demonstrated that the factor controlling the number of $\mathrm{X}$ chromosomes to be eliminated is of maternal origin. Different scenarios can be visualized depending on the relationship between this MF and the imprinting mark determining that only the chromosomes inherited from the father are the ones that can be eliminated:

\section{Scenario 1}

The MF functions to promote X chromosome elimination. Under this scenario, this MF is the elimination factor that directly recognizes the imprinting mark on the imprinted chromosome. The amount of elimination factor determines the number of X chromosomes to be eliminated. Thus, the MF shows a dual role: it causes X chromosome elimination, and it controls the number of $\mathrm{X}$ chromosomes that become eliminated. This scenario corresponds to the 1-factor model of Sánchez and Perondini [1999].
98 


\section{Scenario 2}

The MF functions to prevent X chromosome elimination. Under this scenario, it is necessary to postulate the existence of an elimination factor that directly recognizes the imprinting mark on the imprinted chromosome, and the MF would counteract the function of the elimination factor. The MF is always functional and has a single function, namely to control the number of eliminated X chromosomes by controlling the amount of active elimination factor. This scenario corresponds to the 2-factor model of Sánchez and Perondini [1999].

For each of these 2 scenarios, 2 situations can be encountered:

\section{Situation A}

The default state of the elimination factor is active; it interacts with the ordinary $\mathrm{X}$ chromosome causing its elimination whatsoever its parental origin. In this case, the imprinting mark refers to the inability of the imprinted chromosome to interact with the elimination factor. This would imply that imprinting occurs in the mother, since the chromosome that becomes eliminated is the one inherited from the father: the imprinter factor functions during oogenesis to mark the maternal X chromosome so that this will not interact with the elimination factor.

\section{Situation B}

The default state of the elimination factor is inactive; it does not interact with the ordinary $\mathrm{X}$ chromosome whatsoever its parental origin. In this case, the imprinting mark refers to the ability of the imprinted chromosome to interact with the elimination factor. This would imply that imprinting occurs in the father, since the $\mathrm{X}$ chromosome that becomes eliminated is the one inherited from the father: the imprinter factor functions during spermatogenesis to mark the paternal X chromosome so that this will interact with the elimination factor. A modified version of this situation is to consider that the elimination factor is always function$\mathrm{al}$, and the imprinting mark would cause an advantage to the paternally imprinted $X$ chromosome against the maternally inherited one for binding the elimination factor, as if the paternal X chromosome would sequester this factor.

These logical considerations can be applied to the elimination of all paternal chromosomes during spermatogenesis in sciarid males, although the molecular mechanisms underlying chromosome elimination in the soma and in the germ line are different. Similarly, it can also be extended to the elimination (diaspidoid mechanism) or heterochromatinization (lecanoid mechanism) of all paternal chromosomes in the coccids.

Imprinting and Sex Determination

\section{Evolutionary Considerations}

A set of hypotheses has been proposed to understand the evolution of genomic imprinting: its origin and its maintenance [for reviews see Hurst, 1997; Spencer, 2000 and cites therein]. On the other hand, many theoretical studies have been done to understand the driving forces operating on the evolution of sex determination mechanisms [Werren and Beukeboom, 1998; Kozielska et al., 2010 and cites therein]. To my knowledge, however, theoretical studies on imprinting in relation to sex determination systems based on either elimination or inactivation of chromosomes has received little attention.

Haig, who presented evolutionary models for the sciarid [Haig, 1993b] and coccid [Haig, 1993a] mechanisms, has studied the evolution of the type of sex determination systems treated in this review. He proposed that these mechanisms are the outcome of an intragenomic conflict between male- and female-biased sex ratio effects of the gene functions arising in the population. He suggested the following evolutionary scenario for the sciarids: a driving $\mathrm{X}$ chromosome that gained a transmission advantage causing female-biased sex ratio arose in the population. This produced a situation that was exploited by the maternal autosomes to segregate with the X chromosome at spermatogenesis. The female-biased sex ratio was counteracted by selection of maternal effect genes causing the transformation of the $\mathrm{XX}$ zygotes into $\mathrm{X} 0$ males by the loss of the derived paternal X chromosome together with the transformation of some X chromosomes into the germ-limited $\mathrm{L}$ chromosomes that produced a male-biased sex ratio. Finally, an X' chromosome came into existence that suppressed the effects of the $\mathrm{L}$ chromosomes. In the case of the coccids, the evolutionary scenario from the ancestral XX/X0 mechanism comprises the following steps: first, a meiotic-driving $\mathrm{X}$ chromosome in X0 male that causes female-biased sex ratio was originated. Second, this X-driving effect created a situation that was exploited by the maternal autosomes to evolve effective sex linkage. Finally, maternal effect genes were selected that transform some XX zygotes into males.

Haig [1993b] gave an evolutionary role to the L chromosomes in shaping the sciarid sex determination mechanism. He assumed that the original $\mathrm{L}$ chromosome originated from a paternal $\mathrm{X}$ chromosome $\left(\mathrm{X}^{*}\right.$ in his terminology) that behaved as a maternal $\mathrm{X}$ during spermatogenesis, causing a male-biased sex ratio by killing $\mathrm{XXX}^{*}$ daughters, so that at the beginning, the $\mathrm{X}^{*}$ was transmitted from father to son. Later, the $\mathrm{X}^{*}$ became heterochromatic (lost gene functions) and could survive in 
females and consequently pass to them, increasing its number and acquiring the present L status. A clear prediction of this proposal is that all the $\mathrm{L}$ chromosomes are descendants from that modified $X^{*}$ chromosome. Recent molecular data challenged this contention. Escribá et al. [2011b] microdissected and microcloned the pericentromeric region of the $S$. coprophila $\mathrm{X}$ chromosome, where the rDNA is located. They identified and characterized repeated DNA sequences, a RTE element and an AT-rich satellite, and as expected, rDNA clones were also recovered. In situ chromosome hybridization of these sequences revealed that some of them hybridized to some, but not all L chromosomes, while others did not hybridize to any of the $\mathrm{L}$ chromosomes. All of them showed positive hybridization to the $\mathrm{X}$ chromosome. In addition, the rDNA only hybridized to the $\mathrm{X}$ and not to any of the L chromosomes. These results suggest that not all L chromosomes derived from a modified $\mathrm{X}^{*}$ chromosome. Therefore, the role of $\mathrm{L}$ chromosomes in the evolution of the sciarid sex determination system remains open. Not all sciarid flies carry germ-line-limited L chromosomes. Why were the L chromosomes maintained? A possibility is that they exert a necessary structural or functional role in germ line development.

The germ line E chromosomes in Cecydomyiidae parallel the sciarid $\mathrm{L}$ chromosomes in that they are eliminated from the somatic cells and maintained in the germ line but, in contrast to Sciara, the E chromosomes are also eliminated during the first meiotic division in spermatogenesis, so that they showed female-biased transmission. It may well be that $\mathrm{E}$ chromosomes are maintained because of their requirement for normal development of the female germ line.

None of the studies mentioned above explicitly considered genomic imprinting. An evolutionary population genetic approach, where maternal versus paternal imprinting has been explicitly included, is underway to study the evolutionary steps from the ancestral XX/X0 mechanism of sex determination to the extant one present in sciarids and coccids [Sánchez, 2012; analysis in progress]. Preliminary results showed that the elimination of paternal chromosomes was compatible with maternal, but not with paternal imprinting in both sciarids and coccids. This theoretical result confirms the intuition that there is a link between maternal versus paternal imprinting and elimination/inactivation of maternal versus paternal chromosomes. It is important to keep in mind that the own imprinter gene (encoding the imprinter factor) that determines the chromosome imprinting is also subject to the elimination process. Intuitively, when talk- ing about maternal imprinting in relation to elimination of paternal chromosomes, it is expected that the imprinter gene that acts during oogenesis can be fixed in the population because the imprinting effect is 'not to be eliminated'. In contrast, when talking about paternal imprinting in relation to elimination of paternal chromosomes, it is expected that the imprinter gene that acts during spermatogenesis gets lost from the population because the imprinting effect is 'to be eliminated'. It is proposed that maternal and paternal imprinting in relation to chromosome elimination/inactivation constitute the 2 faces of the sex determination 'coin': elimination/inactivation of paternal chromosomes being associated with maternal imprinting and elimination/inactivation of maternal chromosomes being associated with paternal imprinting. Heterochromatic (inactivated) nuclei do not form sperm and disintegrate so that males only transmit the maternally inherited chromosomes to the next generation.

\section{Perspectives}

There is a plethora of sex determination mechanisms [Bull, 1983]. The comprehension of how these different sex determination mechanisms evolved requires the knowledge of the genetic basis underlying the sex determination pathways in different species. Due to the plethora of different mechanisms controlling sex determination in insects, these are a particularly favorable group of animals in which to study this problem. The search in different insects for the sex determination genes is underway [reviewed in Sánchez, 2008; Verhulst et al., 2010; Gempe and Beye, 2011]. The genetic basis underlying sex determination mechanisms based on elimination/inactivation of chromosomes has received little attention. This is mainly due to these insects being genetically less tractable because of their aberrant chromosome cycles. However, the development of new molecular biology techniques, such as the analysis of transcriptomes, make it now possible to undertake the characterization of genes involved in controlling sex determination in these insects. To this respect, Sciara has been proposed as an experimental model for studies on the evolutionary relationships between the zygotic, maternal and environmental primary signals for sexual development, since in this dipteran, the zygotic signal is a consequence of the maternal signal, and this in turn can be a consequence of the environmental signal (a detailed justification can be found in Sánchez [2010]). 
Two main features of its sex determination mechanism endow Sciara its status of a reference species for sex determination mechanisms based on elimination/inactivation of imprinted chromosomes: the existence of monogenic species and the knowledge about the chromosomal location of the cis-acting CE that participates in the control of $\mathrm{X}$ chromosome elimination. The monogenic species offer the unique possibility of analyzing males versus females at any developmental stage: any desired quantity of male and female embryos, larvae or pupae could be separately collected for transcriptome analysis to identify sex-specific expressed genes and/or sex-specific splicing mRNAs isoforms. Gynogenic (female producers) and androgenic (male producers) females differ in the production of the MF that controls the number of X chromosomes that become eliminated in the XXX zygote. Therefore, the comparison of transcriptomes and/or 2Dgels of total protein extracts (reverse genetics) from oocytes of both types of females would a priori allow to identify the MF, whether it is present in gynogenic oocytes and absent in the androgenic ones or if it is in both although at different amounts. With respect to its molecular nature, the $\mathrm{CE}$ is located in the middle heterochromatic block of the pericentromeric region of the X chromosome of S. coprophila [Crouse, 1960a, b, 1977, 1979]. Microdissection and microcloning of this region have already been performed [Escribá et al., 2011b] so that the molecular characterization of this region is now possible.

Once it is known the molecular basis of the imprinting mark, the identification of the imprinter factor is a priori feasible, based on where the gene encoding this factor is expressed: either in ovaries (maternal imprinting) or in testis (paternal imprinting). The comparison of transcriptomes and/or 2D-gels of total protein extracts from ovaries and testis would help to identify the imprinter factor. It is expected to find many differences between ovaries and testis, yet the molecular nature of the imprinting mark will help to find the imprinter factor. For explanation purposes, let us consider that the imprinting mark is implemented by methylation of the maternal chromosomes and that the imprinted factor is a specific DNA methyltransferase that is exclusively expressed in the mother during oogenesis. Among the differences between ovary and testis transcriptomes, attention should be paid on methyltransferases specifically expressed in the ovaries.

An important aspect of this type of analyses is to have a functional test to ensure that what has been isolated and characterized really corresponds to what was being sought, for example, the MF. However, the standard methodology for the functional tests is not applicable to Sciara because this has not a well-developed genetics. Moreover, production of transgenic Sciara flies is a technically difficult task since the eggs are very fragile so that the microinjection of dsRNA/dsDNA is not technically useful [Perondini ALP and Sánchez L, personal observations]. Instead, other methodologies such as electroporation, which has been successfully used for introduction of DNA into Drosophila [Kamdar et al., 1992] and Bombyx [Shamila and Mathavan, 1998; Guo et al., 2004] eggs, can substitute the more standard methodologies. Thus, for instance, let us imagine that a gynogenic specific mRNA has been identified after comparison of the transcriptomes of ovaries from gynogenic and androgenic females, and let us assume, for explanation purposes, that it corresponds to the gene encoding the wanted MF. If this mRNA is introduced into eggs from androgenic females through electroporation, before the X chromosome elimination process starts, this mRNA will be translated when the zygotic transcription is initiated so that MF will be produced in eggs devoid of this factor. Inspection of these eggs at the syncytial blastoderm stage will show 2 classes of somatic nuclei: those eliminating $2 \mathrm{X}$ chromosomes, as expected for coming from androgenic females, together with nuclei eliminating $1 \mathrm{X}$ chromosome by the action of the exogenous MF. The same logic applies if the MF was not a protein by a noncoding RNA. Electroporation, including the use of dsRNA to impair endogenous genetic functions, may constitute a useful tool for functional studies in insects where the most standard methodologies are not straightforward applicable.

\section{Acknowledgements}

I thank C. Goday, M.F. Ruiz and L. Beukeboom for their comments and suggestions on the manuscript.

\footnotetext{
References Achwal CW, Iyer CA, Chandra HS: Immunochemical evidence for the presence of $5 \mathrm{mC}$, $6 \mathrm{~mA}$ and $7 \mathrm{mG}$ in human, Drosophila and mealybug DNA. FEBS Lett 158:353-358 (1983).

-Adenot PG, Mercier Y, Renard JP, Thompson EM: Differential H4 acetylation of paternal and maternal chromatin precedes DNA replication and differential transcriptional activity in pronuclei of 1-cell mouse embryos. Development 124:4615-4625 (1997).
} 
Amabis JM, Reinach FC, Andrews N: Spermatogenesis in Trichosia pubescens (Diptera: Sciaridae). J Cell Sci 36:199-213 (1979).

Barnes HF: Experimental inter-breeding of the Hessian fly from Kansas, USA, Germany and England. Z Pflanzenk Pflanzen 65:333-343 (1958).

- Berry RO: Observations on chromosome elimination in the germ cells of Sciara ocellaris. Proc Natl Acad Sci USA 25:125-127(1939).

- Berry RO: Chromosome behavior in the germ cells and development of the gonads in Sciara ocellaris. J Morphol 68:547-583 (1941).

- Beukeboom LW, Kamping A, van de Zande L: Sex determination in the haplodiploid wasp $\mathrm{Na}$ sonia vitripennis (Hymenoptera: Chalcidoidea): a critical consideration of models and evidence. Semin Cell Dev Biol 18:371-378 (2007).

Bongiorni S, Cintio O, Prantera G: The relationship between DNA methylation and chromosome imprinting in the coccid Planococcus citri. Genetics 151:1471-1478 (1999).

- Bongiorni S, Mazzuoli M, Masci S, Prantera G: Facultative heterochromatization in parahaploid male mealybugs: involvement of a heterochromatin-associated protein. Development 128:3809-3817 (2001).

Bongiorni S, Pasqualini B, Taranta M, Singh PB, Prantera G: Epigenetic regulation of facultative heterochromatinisation in Planococcus citri via the $\mathrm{Me}(3) \mathrm{K} 9 \mathrm{H} 3-\mathrm{HP} 1-\mathrm{Me}(3) \mathrm{K} 20 \mathrm{H} 4$ pathway. J Cell Sci 120:1072-1080 (2007).

- Bongiorni S, Pugnali M, Volpi S, Bizzaro D, Singh $\mathrm{PB}$, Prantera G: Epigenetic marks for chromosome imprinting during spermatogenesis in coccids. Chromosoma 118:501-512 (2009).

Brown SW: Adaptive status and genetic regulation in major evolutionary changes of coccid chromosome systems. Nucleus 20:145-157 (1977).

Brown SW, Bennett FD: On sex determination in the diaspine scale Pseudaulacaspis pentagona (Targ.) (Coccoidea). Genetics 42:510-523 (1957).

Brown SW, Chandra HS: Chromosome imprinting and the differential regulation of homologous chromosomes, in Goldstein L, Prescott DM (eds): Cell Biology: Genetic Mechanisms of Cells, vol 1: A Comprehensive Treatise, pp 109-189 (Academic Press Inc., New York 1977).

Brown SW, McKenzie HL: Evolutionary patterns in the armored scale insects and their allies. Hilgardia 33:140-170 (1962).

-Brown SW, Nelson-Rees WA: Radiation analysis of a lecanoid genetic system. Genetics 46:9831007 (1961).

-Brown SW, Nur U: Heterochromatic chromosomes in the coccids. Science 145:130-136 (1964).

Buglia GL, Ferraro M: Germline cyst development and imprinting in male mealybug Planococcus citri. Chromosoma 113:284-294 (2004).
Bull JJ: Evolution of Sex Determining Mechanisms (The Benjamin/Cummings Publishing Company Inc., Menlo Park 1983).

Conrad T, Akhtar A: Dosage compensation in Drosophila melanogaster: epigenetic fine-tuning of chromosome-wide transcription. Nat Rev Genet 13:123-134 (2012).

Cowell IG, Aucott R, Mahadevaiah SK, Burgoyne PS, Huskisson N, et al: Heterochromatin, $\mathrm{HP} 1$ and methylation at lysine 9 of histone $\mathrm{H} 3$ in animals. Chromosoma 111:22-36 (2002).

Crouse HV: Translocations in Sciara; their bearing on chromosome behavior and sex determination. Univ Missouri Res Bull 379:1-75 (1943).

Crouse HV: The nature of the influence of $\mathrm{X}$-translocations on sex of progeny in Sciara coprophila. Chromosoma 11:146-166 (1960a).

Crouse HV: The controlling element in sex chromosome behavior in Sciara. Genetics 45: 1429-1443 (1960b).

Crouse HV: X heterochromatin subdivision and cytogenetic analysis in Sciara coprophila (Diptera, Sciaridae). I. Centromere localization. Chromosoma 63:39-55 (1977)

Crouse HV: X heterochromatin subdivision and cytogenetic analysis in Sciara coprophila (Diptera, Sciaridae). II. The controlling element. Chromosoma 74:219-239 (1979).

da Cunha PR, Granadino B, Perondini ALP, Sánchez L: Dosage compensation in sciarids is achieved by hypertranscription of the single $X$ chromosome in males. Genetics 138:787-790 (1994).

Dallai R, Fanciulli PP, Frati F: Chromosome elimination and sex determination in springtails (Insecta, Collembola). J Exp Zool 285:215225 (1999).

Dallai R, Fanciulli PP, Frati F: Aberrant spermatogenesis and the peculiar mechanism of sex determination in Symphypleona Collembola (Insecta). J Hered 91:351-358 (2000).

Dallai R, Fanciulli PP, Carapelli A, Frati F: Aberrant spermatogenesis and sex determination in Bourletiellidae (Hexapoda, Collembola), and their evolutionary significance. Zoomorphology 120:237-245 (2001).

Davidheiser B: Inheritance of the X chromosome in exceptional males of Sciara ocellaris (Diptera). Genetics 28:193-199 (1943).

de Saint-Phalle B, Sullivan W: Incomplete sister chromatid separation is the mechanism of programmed chromosome elimination during early Sciara coprophila embryogenesis. Development 122:3775-3784 (1996).

Devajyothi C, Brahmachari V: Detection of a CpA methylase in an insect system: characterization and substrate specificity. Mol Cell Biochem 110:103-111 (1992).

-Du Bois AM: Chromosome behavior during cleavage in the eggs of Sciara coprophila (Diptera) in the relation to the problem of sex determination. Cell Tissue Res 19:595-614 (1933).
Epstein H, James TC, Singh PB: Cloning and expression of Drosophila HP1 homologs from a mealybug, Planococcus citri. J Cell Sci 101: 463-474 (1992).

Escribá MC, Giardini MC, Goday C: Histone H3 phosphorylation and non-disjunction of the maternal X chromosome during male meiosis in sciarid flies. J Cell Sci 124:1715-1725 (2011a).

Escribá MC, Greciano PG, Méndez-Lago M, de Pablos B, Trifonov VA, et al: Molecular and cytological characterization of repetitive DNA sequences from the centromeric heterochromatin of Sciara coprophila. Chromosoma 120:387-397 (2011b).

Esteban MR, Campos MCC, Perondini ALP, Goday C: Role of microtubules and microtubule organizing centers on meiotic chromosome elimination in Sciara ocellaris. J Cell Sci 110: 721-730 (1997).

- Ferraro M, Buglia GL, Romano F: Involvement of histone $\mathrm{H} 4$ acetylation in the epigenetic inheritance of different activity states of maternally and paternally derived genomes in the mealybug Planococcus citri. Chromosoma 110:93-101 (2001).

Fuge H: Unorthodox male meiosis in Trichosia pubescens (Sciaridae). Chromosome elimination involves polar organelles degeneration and monocentric spindles in first and second division. J Cell Sci 107:299-312 (1994).

Gallun RL, Deay HO, Cartwright WB: Four Races of Hessian Fly Selected and Developed from an Indiana Population (Purdue University Agricultural Experiment Station, West Lafayette 1961).

Gempe T, Beye M: Function and evolution of sex determination mechanisms, genes and pathways in insects. Bioessays 33:52-60 (2011).

- Gerbi SA: Unusual chromosome movements in sciarid flies, in Hennig W (ed): Germ Line Soma Differentiation (Results \& Problems in Cell Differentiation), pp 71-104 (SpringerVerlag, Berlin 1986).

Goday C, Esteban MR: Chromosome elimination in sciarid flies. Bioessays 23:242-250 (2001).

Goday C, Ruiz MF: Differential acetylation of histones $\mathrm{H} 3$ and $\mathrm{H} 4$ in paternal and maternal germline chromosomes during development of sciarid flies. J Cell Sci 115:4765-4775 (2002).

-Greciano PG, Goday C: Methylation of histone $\mathrm{H} 3$ at Lys4 differs between paternal and maternal chromosomes in Sciara ocellaris germline development. J Cell Sci 119:4667-4677 (2006).

Guo XY, Dong L, Wang SP, Guo TQ, Wang JY, $\mathrm{Lu} \mathrm{CD}$ : Introduction of foreign genes into silkworm eggs by electroporation and its application in transgenic vector test. Acta Biochim Biophys Sin 36:323-330 (2004)

Haig D: The evolution of unusual chromosome systems in coccids: extraordinary sex ratios revisited. J Evolution Biol 6:69-77 (1993a).

Haig D: The evolution of unusual chromosome systems in sciarid flies: intragenomic conflict and the sex ratio. J Evolution Biol 6:249-261 (1993b). 
Herrick G, Seger J: Imprinting and paternal genome elimination in insects. Results Probl Cell Differ 25:41-71 (1999).

Hurst LD: Evolutionary theories of genomic imprinting, in Reik W, Surani A (eds): Genomic Imprinting (Frontiers in Molecular Biology), pp 211-237 (Oxford University Press, Oxford 1997).

James HC: Sex ratios and the status of the male in Pseudococcinae (hem. Coccidae). B Entomol Res 28:429-461 (1937).

James HC: The effect of the humidity of the environment on sex ratios from over-aged ova of Peudococcus citri (Risso). Proc Roy En So London A 13:73-79 (1938).

-Kamdar P, Von Allmen G, Finnerty V: Transient expression of DNA in Drosophila via electroporation. Nucleic Acid Res 20:3526 (1992).

Kourmouli N, Jeppesen P, Mahadevhaiah S, Burgoyne $\mathrm{P}, \mathrm{Wu} \mathrm{R}$, et al: Heterochromatin and tri-methylated lysine 20 of histone $\mathrm{H} 4$ in animals. J Cell Sci 117:2491-2501 (2004).

-Kozielska M, Weissing FJ, Beukeboom LW, Pen I: Segregation distortion and the evolution of sex-determining mechanisms. Heredity 104: 100-112 (2010).

-Kruhlak MJ, Hendzel MJ, Fischle W, Bertos NR, Hameed S, et al: Regulation of global acetylation in mitosis through loss of histone acetyltransferases and deacetylases from chromatin. J Biol Chem 276:38307-38319 (2001).

Kubai DF: Meiosis in Sciara coprophila: structure of the spindle and chromosome behavior during the first meiotic division. J Cell Biol 93: 655-669 (1982).

Kubai DF: Nonrandom chromosome arrangements in germ line nuclei of Sciara coprophila males: the basis for nonrandom chromosome segregation on the meiosis I spindle. J Cell Biol 105:2433-2446 (1987).

Liu PY: Estudo biologico de cultura de Bradysi tritici (Diptera, Sciaridae) parasitada por gregarina (thesis, Sao Paulo 1968).

Lucchesi JC: The structure-function link of compensated chromatin in Drosophila. Curr Opin Genet Dev 19:550-556 (2009).

-Macdonald WA: Epigenetic mechanisms of genomic imprinting: common themes in the regulation of imprinted regions in mammals, plants, and insects. Genet Res Int 2012:585024 (2012).

-Martín I, Ruiz MF, Sánchez L: The gene transformer-2 of Sciara (Diptera, Nematocera) and its effect on Drosophila sexual development. BMC Dev Biol 11:19 (2011).

Metz CW: Chromosome behavior in Sciara (Diptera). Anat Rec 31:346-347 (1925).

Metz CW: Chromosome behavior, inheritance and sex determination in Sciara. Am Nat 72: 485-520 (1938).

-Metz CW, Schmuck ML: Unisexual progenies and the sex chromosomes mechanism in Sciara. Proc Natl Acad Sci USA 15:863-866 (1929).
Miller DR, Kosztarab M: Recent advances in the study of scale insects. Annu Rev Entomol 24: 1-27 (1979).

Mori L, Perondini ALP: Errors in the elimination of X chromosomes in Sciara ocellaris. Genetics 94:663-673 (1980).

Mori L, Dessen EM, Perondini ALP: A gene that modifies the sex ratio in a bisexual strain of Sciara ocellaris. Heredity 42:353-357 (1979).

Moses MS, Metz CW: Evidence that the female is responsible for the sex ratio in Sciara (Diptera). Proc Natl Acad Sci USA 14:928-930 (1928).

Nelson-Rees WA: A study of sex predetermination in the mealy bug Planococcus citri (risso). J Exp Zool 144:111-137 (1960).

Nigro RG, Campos CC, Perondini ALP: Temperature and the progeny sex-ratio in Sciara ocellaris (Diptera, Sciaridae). Genet Mol Biol 30: 152-158 (2007).

Nur U: Meiotic parthenogenesis and heterochromatization in a soft scale, Pulvinaria hydrangeae (Coccoidea: Homoptera). Chromosoma 14:123-139 (1963).

-Nur U: Heterochromatization and euchromatization of whole genomes in scale insects (Coccoidea: Homoptera). Dev Suppl 1990:29-34 (1990).

Painter RH: Observations on the biology of the Hessian fly. J Econ Entomol 23:326-328 (1930).

Perondini ALP: Elimination of X chromosomes and the problem of sex determination, in Chatterjee R, Sánchez L (eds): Genome Analysis in Eukaryotes: Developmental and Evolutionary Aspects, pp 149-166 (Springer-Verlag, Berlin 1998).

Perondini ALP, Ribeiro AF: Chromosome elimination in germ cells of Sciara embryos: involvement of the nuclear envelope. Invertebr Reprod Dev 32:131-141 (1997).

Perondini ALP, Gutzeit HO, Mori L: Nuclear division and migration during early embryogenesis of Bradysia tritici Coquillet (syn. Sciara ocellaris) (Diptera: Sciaridae). Int J Insect Morphol 15:155-163 (1986).

Prantera G, Bongiorni S: Mealybug chromosome cycle as a paradigm of epigenetics. Genet Res Int 2012:867390 (2012).

Rieffel SM, Crouse HV: The elimination and differentiation of chromosomes in the germ line of Sciara. Chromosoma 19:231-276 (1966).

Rocha LS, Perondini ALP: Analysis of the sex ratio in Bradysia matogrossensis (Diptera, Sciaridae). Genet Mol Biol 23:97-103 (2000).

Ruiz MF, Esteban MR, Doñoro C, Goday C, Sánchez L: Evolution of dosage compensation in Diptera: the gene maleless Implements dosage compensation in Drosophila (Brachycera suborder) but its homolog in Sciara (Nematocera suborder) appears to play no role in dosage compensation. Genetics 156:1853-1865 (2000).
Ruiz MF, Goday C, González P, Sánchez L: Molecular analysis and developmental expression of the Sex-lethal gene of Sciara ocellaris (Diptera order, Nematocera suborder). Gene Expr Patterns 3:341-346 (2003).

Sánchez L: Sex-determining mechanisms in insects. Int J Dev Biol 52:837-856 (2008).

Sánchez L: Sciara as an experimental model for studies on the evolutionary relationships between the zygotic, maternal and environmental primary signals for sexual development. J Genet 89:325-331 (2010).

-Sánchez L: Evolutionary considerations on sex determination mechanisms based on imprinting an elimination of the $\mathrm{X}$ chromosome, p 29. 16th Evolutionary Biology Meeting, Marseilles, 2012

Sánchez L, Perondini ALP: Sex determination in sciarid flies: a model for the control of differential X-chromosome elimination. J Theor Biol 197:247-259 (1999).

- Serna E, Gorab E, Ruiz MF, Goday, C, EirínLópez JM, Sánchez L: The gene Sex-lethal of the Sciaridae family (order Diptera, suborder Nematocera) and its phylogeny in dipteran insects. Genetics 168:907-921 (2004).

Sha K: A mechanistic view of genomic imprinting. Annu Rev Genomics Hum Genet 9:197216 (2008)

Shamila Y, Mathavan S: Gene transfer in silkworm Bombyx mori via electroporation. Biotechnol Tech 12:507-510 (1998).

Spencer HG: Population genetics and evolution of genomic imprinting. Annu Rev Genet 34: 457-477 (2000).

-Stuart JJ, Hatchett JH: Cytogenetics of the Hessian fly, Mayetiola destructor (Say). I. Mitotic karyotype analysis and polytene chromosome correlations. J Hered 79:184-189 (1988a).

Stuart JJ, Hatchett JH: Cytogenetics of the Hessian fly, Mayetiola destructor (Say). II. Inheritance and behavior of somatic and germ-line-limited chromosomes. J Hered 79:190-199 (1988b).

Stuart JJ, Hatchett JH: Genetics of sex determination in the Hessian fly, Mayetiola destructor. J Hered 82:43-52 (1991).

-Verhulst EC, van de Zande L, Beukeboom LW: Insect sex determination: it all evolves around transformer. Curr Opin Genet Dev 20:376383 (2010)

Volpi S, Bongiorni S, Prantera G: HP2-like protein: a new piece of the facultative heterochromatin puzzle. Chromosoma 116:249-258 (2007).

Werren JH, Beukeboom LW: Sex determination, sex ratios, and genetic conflict. Annu Rev Ecol Syst 29:233-261 (1998).

Whalley P, Jarzembowski EA: A new assessment of Rhyniella, the earliest known insect, from the Devonian of Rhynie, Scotland. Nature 291:317 (1981).

White MJD: Animal Cytology and Evolution, ed 3 (Cambridge University Press, Cambridge 1973). 